\section{¿UNA NUEVA ELITE POLÍTICA? PERFIL SOCIOLÓGICO DE LOS} GABINETES INICIALES DE CAMBIEMOS

\author{
A NEW POLITICAL ELITE? SOCIOLOGICAL PROFILE \\ OF THE INITIAL CABINETS OF «CAMBIEMOS»
}

\section{PAULA CANELO .}

Consejo Nacional de Investigaciones Científicas y Técnicas, Instituto de Investigaciones Sociales de América Latina (IICSAL-FLACSO-CONICET); Facultad de Ciencias Sociales de la Universidad de Buenos Aires (FCS-UBA). pvcanelo@yahoo.com

\section{Resumen}

El artículo propone un análisis empírico y sistemático sobre tres gabinetes del gobierno de Cambiemos en la Argentina: el de Mauricio Macri en la Nación, el de María Eugenia Vidal en la provincia de Buenos Aires, y el de Horacio Rodríguez Larreta en la Ciudad Autónoma de Buenos Aires. El estudio permite, primero, caracterizar el perfil sociológico general que presentó esta elite política ejecutiva a partir de 2015; segundo, mostrar las similitudes y diferencias que presentaron los tres gabinetes comparados; tercero, identificar continuidades y rupturas en ciertas tendencias generales de la configuración de las elites políticas argentinas, vinculando a estos gabinetes con otros, de gobiernos previos; y finalmente, evaluar en qué medida el personal político de Cambiemos constituyó, o no, una nueva elite política en la Argentina reciente.

\section{Descriptores}

sociología de las elites / elite política / gabinetes / Cambiemos / Argentina

\section{ESTUDIOS SOCIALES}

revista universitaria semestral ·

año XXXI $\cdot n^{\circ} 60 \cdot$ Santa $\mathrm{Fe} \cdot$ Argentina

Universidad Nacional del Litoral .

enero-junio · 2021 [ ISSNe 2250-6950 ]

DOI [ 10.14409/es.v6011.8959 ] ·PP [ 143-182 ]

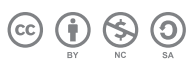

\section{Abstract}

The article proposes an empirical and systematic analysis of the three cabinets of the government of «Cambiemos» in Argentina: that of Mauricio Macri in the Nation, that of María Eugenia Vidal in the province of Buenos Aires, and that of Horacio Rodríguez Larreta in the Autonomous City of Buenos Aires. The study will allow, first, to characterize the general sociological profile presented by this executive political elite as of 2015; second, to show the similarities and differences presented by the three cabinets compared; third, to identify continuities and ruptures in certain general trends in the configuration of Argentine political elites, linking these cabinets with others, designated by previous governments; and finally, to assess the extent to which the political personnel of "Cambiemos» constituted, or not, a new political elite in recent Argentina.

\section{Describers}

elite sociology / political elite / cabinets / Cambiemos / Argentina

Recibido: 04 / 02 / 2020 Aprobado: 22 / 05 / 2020

1] Este artículo presenta una profundización de algunas cuestiones trabajadas en versión preliminar en Canelo (2019). 


\section{INTRODUCCIÓN}

A poco de concluido en la Argentina el ciclo nacional de gobierno de la coalición Cambiemos (formada por los partidos Propuesta Republicana, Coalición Cívica y Unión Cívica Radical), es evidente que éste ha constituido un fenómeno político singular. Por un lado, porque fue la primera experiencia de gobierno, a nivel nacional, de un partido de derecha triunfante en elecciones libres y competitivas de toda la historia argentina. Pero que, luego de una sorprendente performance electoral en las intermedias de 20I7, licuó muy rápidamente dicho caudal para, producto de la combinación de una profunda crisis socioeconómica y política, ser derrotado en forma contundente por el recientemente formado Frente de Todos en las elecciones de octubre de 2019.

La singularidad de la experiencia de Cambiemos reside en que, por otro lado, su gobierno logró conciliar la implementación de un feroz ajuste económico con un importante respaldo electoral, que incluyó el de aquellos sectores perjudicados por dichas políticas, frente a una aguda desorientación de la oposición. Y finalmente, porque Cambiemos posibilitó el ascenso a las más altas posiciones de poder político de una elite gobernante con un perfil sociológico distintivo.

Por el momento, la reflexión sobre Cambiemos y su experiencia de gobierno es aún fragmentaria y heterogénea, y en la misma se combinan algunos influyentes ensayos, muchos periodísticos, con importantes aportes sociológicos y politológicos sobre algunos aspectos puntuales, como los orígenes de la coalición, la integración de sus cuadros de gobierno, sus estrategias de legitimación social y algunas de sus principales políticas públicas (BELLONI Y CANTAMUTTO, 2OI9; BELLOTTI, MORRESI Y VOMMARO, 2OI5; CANELO, 2OI9; CANELO Y CASTELLANI, 2OI7; CANELO Y LASCURAIN, 2OI7; FIDANZA, 2OI9; MAURO, 2OI5: 407-43O; MORRESI, 2OI5: I63-2OI; NATANSON, 2OI8; ROVETTO Y GINDIN, 2OI9; VOMMARO, 2OI7; VOMMARO Y MORRESI, 2OI5).

En ese panorama diverso se encuentran ya relativamente consolidados algunos consensos que tienden a permear tanto los espacios académicos e intelectuales como el más llano sentido común, acerca de la especificidad que habría presentado esta experiencia gubernamental. El acuerdo más contundente y generalizado, que ha tendido a convertirse en una clave central de la discusión pública sobre Cambiemos, es aquel que lo caracteriza como un "gobierno de CEO» O "CEOcracia»: es decir, un gobierno integrado primordialmente por individuos que han ocupado los puestos de mayor responsabilidad en empresas u organizaciones corporativas. Así, se ha tendido a convenir que el rasgo que distinguiría a esta experiencia gubernamental 
de otras, tanto pasadas como contemporáneas, es la influencia decisiva del «perfil empresarial» en el conjunto del personal político.

$\mathrm{El}$ "gobierno de los CEO» se ha consagrado así como la clave interpretativa fundamental que definiría al gobierno de Cambiemos. Para los partidarios del gobierno, reclutar CEO al frente del gobierno y del Estado era garantía de buena gestión, dado que los mismos, se afirmaba, encarnaban valores como el éxito, la transparencia o la eficiencia, precisamente aquellos que «tanta falta hacían» en los espacios estatales argentinos. ¿Qué mejor garantía de gobierno eficaz y transparente que ser un "gobierno de los CEO", individuos que condensan varias de las «meritocracias» posibles? Desde el discurso opositor, la presencia de estos Ceo fue la confirmación de que el de Cambiemos era «un gobierno de ricos», y también la explicación de su estrepitoso fracaso en la gestión. Así por ejemplo se afirmó que gran parte de la crisis del gobierno de Macri habría respondido a la «falta de empatía» o ajenidad de los CEo hacia la sociedad que gobiernan, las exigencias de la política y los requerimientos de la gestión estatal.

Otro consenso muy instalado sobre el gobierno de Cambiemos, vinculado con el anterior, supone que se trató de una «nueva generación» de dirigentes, recién llegados a la política. Se construyó así la imagen de un nuevo grupo social, integrado por miembros de las clases medias altas y altas argentinas, que decidió «meterse en política» por primera vez para contrarrestar la experiencia de «excesiva» politización del ciclo kirchnerista previo (2003-2015). Esto, afirmaba cierto sentido común, garantizaba el compromiso con una nueva forma de hacer política, menos «corrupta y prebendaria», y revelaba la disposición sacrificial de estos cuadros, provenientes de posiciones sociales de privilegio, así como aseguraba altos umbrales de honestidad y/o competencia del nuevo funcionariado. El discurso de los funcionarios sobre el sacrificio de "meterse en política», de abandonar los cómodos espacios de su condición social privilegiada para «embarrarse» en política formó parte de una poderosa «narrativa del don» (VOMMARO y ARMESTO, 20I5: IIO-I32), que fue un capital político privilegiado para Cambiemos (CANELo, 20I9).

Así, durante los primeros años de gobierno se insistía, tanto desde las esferas periodísticas como desde algunos trabajos académicos, sobre nuevas modalidades de reclutamiento del personal político, que se realizaba sobre todo en el sector privado. Se destacaba el importantísimo rol que habrían cumplido en esa tarea las fundaciones Pensar, uno de los think tank del macrismo, y G25, una suerte de «bolsa de trabajo VIP» (vommaro, 20I7) como parte de un acelerado «Plan Semi- 
llero». En noviembre de 20I5, por ejemplo, la prensa calculaba que para cubrir los gabinetes de Nación, PBA y CABA, Cambiemos necesitaba «unos 9000 cuadros nuevos. Un número arrollador: 1500 para la Ciudad, 3500 para la provincia y 4000 para la Nación. No es una tarea sencilla llenar esos puestos para una fuerza que hasta ahora solo gobernaba la Capital $»^{2}$.

La condición de «recién llegados» a la política argentina formó parte fundamental del discurso legitimador de Cambiemos y de la frontera que intentó marcar con la política tradicional. La definición de «nueva generación», que le otorgaba a Cambiemos un flou de novedad y modernización, fue construida en contraposición a los supuestos vicios de dos espacios de los que esta fuerza procuró diferenciarse. Por un lado, el de la «vieja política» sus malas prácticas y costumbres (corrupción, prebenda, nepotismo, ineficiencia, populismo). Por otro lado, el del «estado ineficiente», lugar de la prebenda, el despilfarro, la ineficiencia burocrática.

Así, ambos consensos, el de "gobierno de los CEO» y el de la «nueva generación» que se atreve a «meterse en política», legitimaron en gran parte la propuesta gubernamental de «cambio cultural» de Cambiemos, coherente con su promesa aspiracional, meritocrática y del «mejor equipo» (CANELO, 20I9). Presentarse, en suma, como una «nueva elite política» fue central en el discurso justificador de este gobierno de derecha.

El presente artículo pone en cuestión varios de estos sentidos comunes sobre Cambiemos, a partir de la construcción y análisis de datos empíricos sobre el perfil sociológico de la elite política que ocupó los cargos más altos de los tres gabinetes más importantes de este gobierno: el de Mauricio Macri en la Nación, el de María Eugenia Vidal en la provincia de Buenos Aires (РBA), y el de Horacio Rodríguez Larreta en la Ciudad Autónoma de Buenos Aires (CABA). En trabajos anteriores hemos analizado, primero, y separadamente, el perfil sociológico de dos de estos tres gabinetes, lo que nos posibilitó identificar ciertos rasgos particulares de los equipos de Nación (CANelo y CASTELlani, 20I7), y luego, los contrastes que presentaban éstos con los de la PBa (CANELO y LASCURAIn, 20I7). En CANElo (2019) avanzamos con una comparación preliminar de los tres gabinetes, que nos permitió identificar algunos rasgos comunes y también algunas propiedades distintivas de estos elencos, que profundizamos aquí con nuevos cruces de variables e incorporando datos sobre los perfiles de otros equipos ministeriales de la historia argentina, para colocar nuestras conclusiones en perspectiva.

2] Noticias, 11/11/2015. 
Los gabinetes son dependencias estratégicas para la organización y el funcionamiento del poder gubernamental, y por ello han recibido una significativa atención de las ciencias sociales, especialmente de la ciencia política y la sociología. Aunque las preguntas han variado con la especialización disciplinar, la ciencia política ha tendido a estudiar los gabinetes interesada por las características institucionales del presidencialismo, o las estrategias legislativas del Presidente de la Nación, las tensiones y equilibrios de las coaliciones de gobierno, la construcción de alianzas, etc. (AMORIM NETO, I998; CAMERLO, 2OI3: II9-I42; CHASQUETTI, BUQUET Y CARDARELLO, 2OI3: I5-40; DÁVILA, OLIVARES Y AVENDAÑO, 2OI3: 67-94; DE LUCA, 2OII: 37-48; POMARES, LeIras, Page, ZÁrate, ABDAla, 20I4). Por su parte, la sociología se ha interesado por el estudio de los perfiles de los ministros, por las rupturas y continuidades en las elites políticas, por el grado de especialización y profesionalización del personal político estatal, por los vínculos entre el mundo social y el mundo político (CANELO, 20I6; CANELO Y CASTELLANI, 2OI7; CANELO, CASTELLANI Y HEREDIA, 2OI5; CANELO Y HEREDIA, 2OI9; DE IMAZ, I964; GENÉ, 2OI9; GIORGI, 2OI4: IO3-I39; GIORGI, 2OI5; HEREDIA, 2OI5; HEREDIA, GENÉ Y PERELMITER, 2OI2: 284-290; JOIGNANT Y GUELL, 2OII; LASCURAIN, 2OI7; SALERNO, 2OI9).

Este artículo recurre a una estrategia analítica fructífera para el estudio sobre el personal político, que consiste en clasificarlo según sus propiedades sociales formalizadas en variables (edad, sexo, nivel educativo, etc.) (sAWICKI, I999). Así, se analiza el perfil sociológico de los gabinetes de Cambiemos mediante el estudio de las características sociodemográficas y las trayectorias de todos los hombres y mujeres designados para ocupar las más altas posiciones jerárquicas (o cargos) en los gabinetes iniciales ${ }^{3}$ de Nación, PBA y CABA: ministros, secretarios y subsecretarios, o cargos equivalentes. Se incluyen los 350 individuos nombrados en las 26 dependencias con las que Macri organizó su primer gabinete en Nación ${ }^{4}$; a los 9I individuos que Vidal designó para ocupar las 20 dependencias del gabinete provin-

3] A los efectos de la comparación, se analiza la composición inicial de estos tres gabinetes, la que fuera establecida entre fines de 2015 y principios de 2016, tanto en términos de la composición del organigrama como en términos de la designación de funcionarios. No se incorporan ni las modificaciones del organigrama inicial, ni la eliminación o creación de dependencias, ni las reestructuraciones, ajustes o modificaciones en las jerarquías posteriores a ese período.

4] Se trató de los 20 ministerios, la Jefatura de Gabinete de Ministros y las 5 Secretarías de la Presidencia de la Nación (General, Legal y Técnica, Secretaría de Programación para la Prevención de la Drogadicción y la Lucha contra el Narcotráfico, Agencia Federal de Inteligencia y Casa Militar). 
cial durante sus primeros meses de gobierno $0^{5}$ y a los 84 funcionarios elegidos por Rodríguez Larreta para dirigir las I3 dependencias del gabinete de ciudad en $2015^{6}$.

Las variables incorporadas al análisis son sexo, edad al momento de asumir la posición en el gabinete, máximo nivel educativo alcanzado, tipo de carrera de grado y de posgrado, tipo de establecimiento educativo, participación en ONG, fundaciones y partidos políticos, y algunos datos relevantes de la trayectoria ocupacional de estos individuos, como cargo previo y tipo de cargo ocupado.

Los datos que permitieron reconstruir estas variables son públicos, y las fuentes fueron variadas: publicaciones oficiales (boletines), diarios nacionales y locales, portales periodísticos en Internet, currículum vitae y fichas biográficas de los funcionarios publicados en páginas web y redes sociales, presentaciones en eventos académicos, etc. ${ }^{7}$.

Este análisis empírico y sistemático sobre los tres gabinetes más importantes de Cambiemos permitirá, primero, caracterizar el perfil sociológico general que presentó este encumbrado grupo de la elite política ejecutiva a partir de 20I5; segundo, mostrar las similitudes y diferencias que presentaron los tres gabinetes comparados, identificando rasgos sociológicos específicos a cada uno de ellos y comunes a los tres; tercero, identificar continuidades y rupturas en ciertas tendencias generales de la configuración de las elites políticas argentinas, vinculando estos gabinetes con otros, designados por gobiernos previos; y finalmente, evaluar en qué medida el personal político de Cambiemos constituyó (o no) una nueva elite política en la Argentina reciente.

\section{PERFIL SOCIODEMOGRÁFICO: GÉNERO Y EDAD}

Si bien la ley de cupo sancionada en la Argentina en el año I99i marcó un avance de la presencia de mujeres en las listas legislativas, los altos cargos ejecutivos siguen mostrando una abrumadora presencia masculina. Esto no constituye un rasgo exclusivo de nuestro país: en América Latina se trata de un problema recurrente,

5] En este caso fueron 11 ministerios, 6 secretarías, 1 dirección general (de Cultura y Educación), la Asesoría General de Gobierno y la Coordinación General de la Unidad Gobernador, todas con rango ministerial, según Ley de Ministerios n¹4853, del 30/11/2016.

6] Se trató aquí de 10 ministerios y 3 jefaturas: Jefatura de Gobierno, Jefatura de Gabinete de Ministros y Vicefefatura de Gobierno.

7] Todos los datos y gráficos que se presentan aquí fueron relevados y elaborados por el Observatorio de las Elites del CITRA (CONICET-UMET). 
señalado por diferentes investigaciones (CAMINOTTI Y FREIDENBERG, 2OI6: I2I-I44; CANELO Y LASCURAIN, 2OI7; KROOK Y O'BRIEN, 2OI2: 840-855; ESCOBAR LEMMON Y TAYLOR ROBINSON, 2009: 685-699). Es, además, tanto una tendencia de largo plazo (de los 636 ministros que tuvo el gabinete nacional argentino entre I854 y 2OII, solo el I,73\% fueron mujeres - GIORGI, 20I5), como un rasgo actual de los elencos políticos argentinos: por ejemplo, el gabinete designado en $201 \mathrm{I}$ por la primera mujer elegida presidenta de la historia argentina, Cristina Fernández de Kirchner, solo incluyó un 23\% de mujeres (CANELO Y MARINO, 2020).

GRÁFICO 1:

SEXO DE LOS FUNCIONARIOS DEL GABINETE DE NACIÓN. $\mathrm{N}=350$.

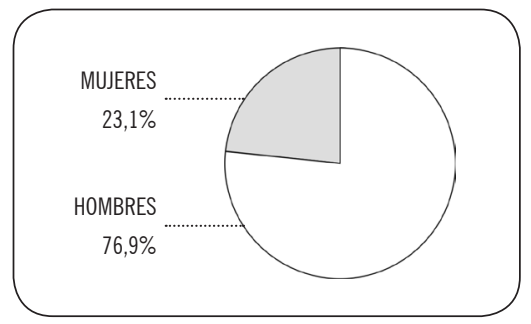

GRÁFICO 2:

SEXO DE LOS FUNCIONARIOS DEL GABINETE DE PBA. $\mathrm{N}=91$

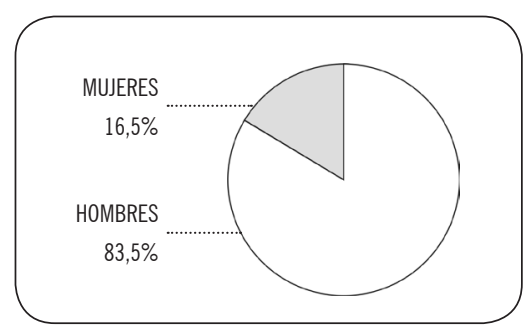

GRÁFICO 3:

SEXO DE LOS FUNCIONARIOS DEL GABINETE DE CABA. $\mathrm{N}=84$

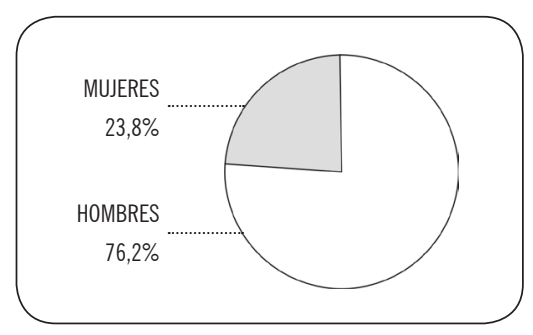

FUENTE (GRÁFICOS 1 A 3):

Observatorio de las Elites del CITRA (CONICET-UMET).

Durante los años de Cambiemos la política continuó siendo un mundo de hombres. Los Gráficos I, 2 y 3 son elocuentes al respecto: las mujeres no llegaron a ocupar ni un cuarto del total de los altos espacios ejecutivos: $23, \mathrm{I} \%$ en Nación, I6,5\% en PBA y 23,8\% en CABA. Es llamativo aquí que el menor porcentaje de mujeres se observe en el gabinete de Vidal, primera gobernadora mujer de la provincia de Buenos Aires. 
Si se observa la distribución de las funcionarias mujeres dentro de las distintas dependencias, la desigualdad de género se profundiza (Gráficos 4, 5 y 6):

GRÁFICO 4

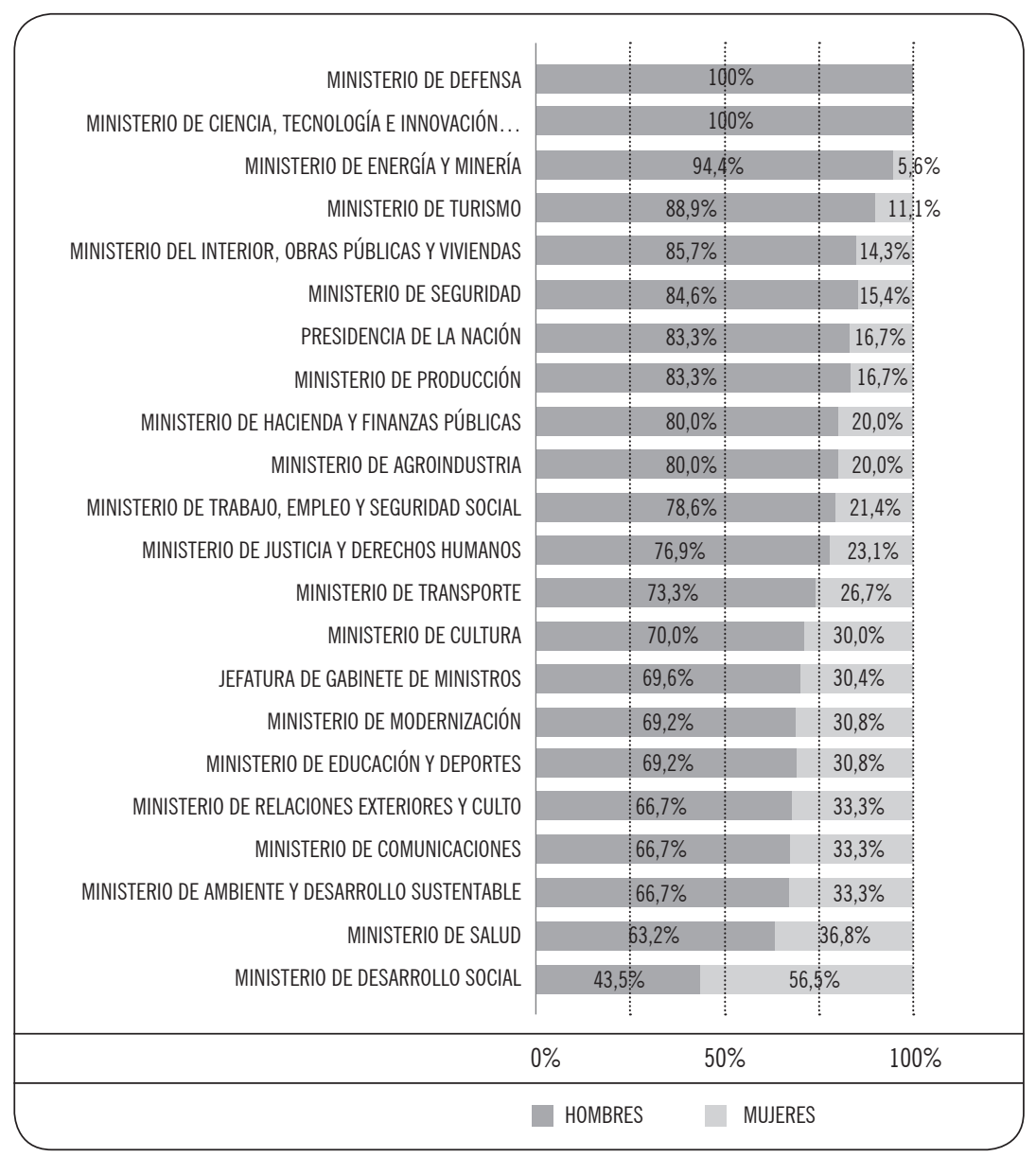

FUENTE: Observatorio de las Elites del CITRA (CONICET-UMET). 
Macri no designó a ninguna funcionaria mujer en las cúpulas de los ministerios de Ciencia y Tecnología ni de Defensa, mientras que en el Ministerio de Energía y Minería las mujeres fueron solo el 5,6\% de la cúpula de la dependencia. Del conjunto del gabinete, el Ministerio de Desarrollo Social (un área de gestión «tradicionalmente femenina»-GRASSI, 1989; SALERNO, 2019) fue donde se observa una mayor presencia femenina $(56,5 \%)$ y la única cartera donde superan a los hombres (CANELO Y CASTELLANi, 2OI7).

GRÁFICO 5:

DEPENDENCIAS DEL GABINETE DE PBA, SEGÚN SEXO. N=91

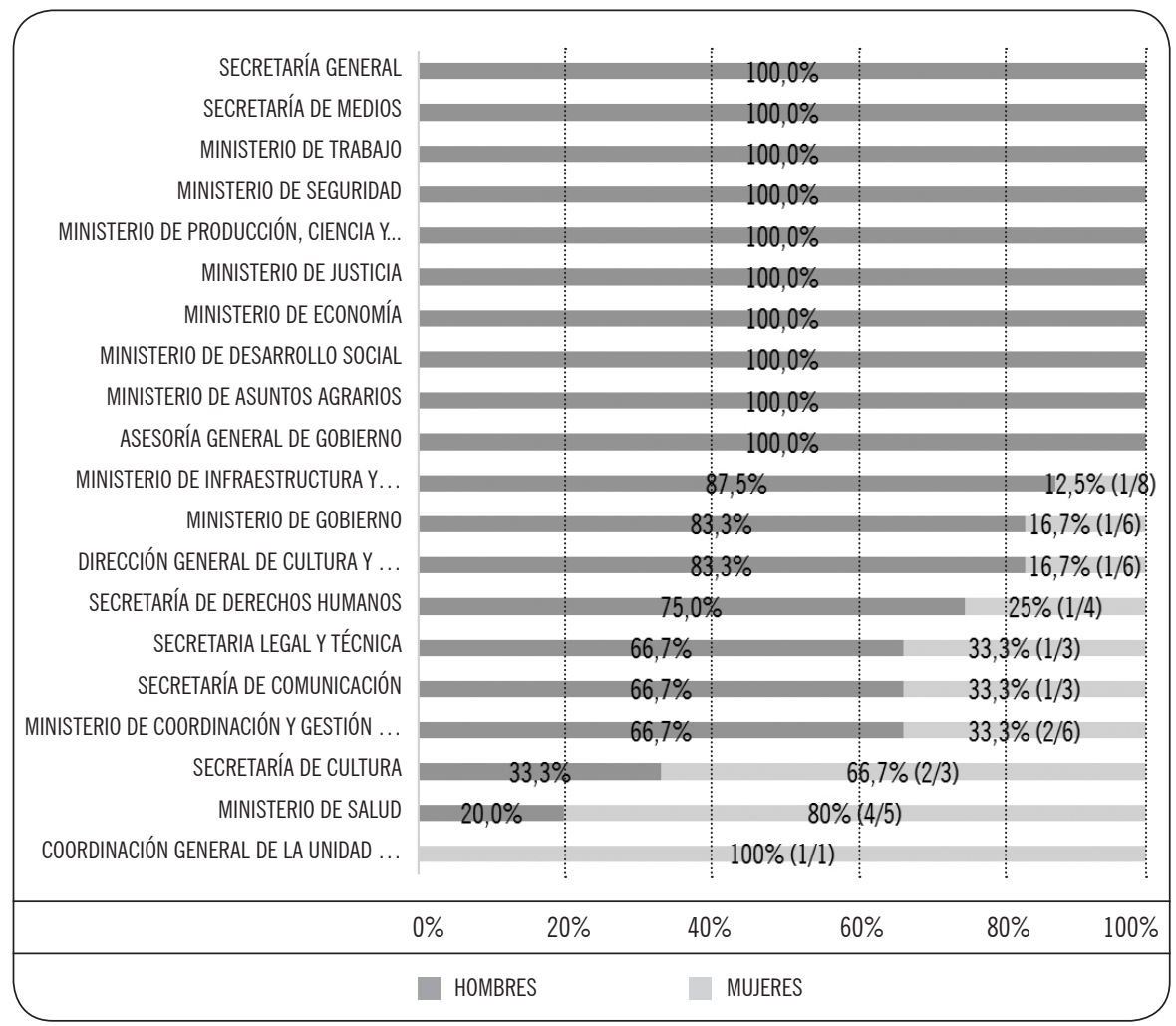

FUENTE: Observatorio de las Elites del CITRA (CONICET-UMET). 
Pese a que Vidal se autoproclamó como una promotora de la «igualdad de oportunidades» (aunque nunca como una feminista) y de quien se hubiera esperado que, por ser mujer, designara un equipo más igualitario, es el gabinete de la PBA el que presenta los peores indicadores de género, con solo un $\mathrm{I} 6,5 \%$ de promedio general. En efecto, como muestra el gráfico 5, la mitad de las dependencias del gabinete de PBA no tuvo ninguna mujer ocupando altos cargos; solo en la Secretaría de Cultura y en el Ministerio de Salud las mujeres superaron a los hombres, con $66,7 \%$ en la primera y $80 \%$ en el segundo ${ }^{8}$.

GRÁFICO 6:

DEPENDENCIAS DEL GABINETE DE CABA, SEGÚN SEXO. N=84

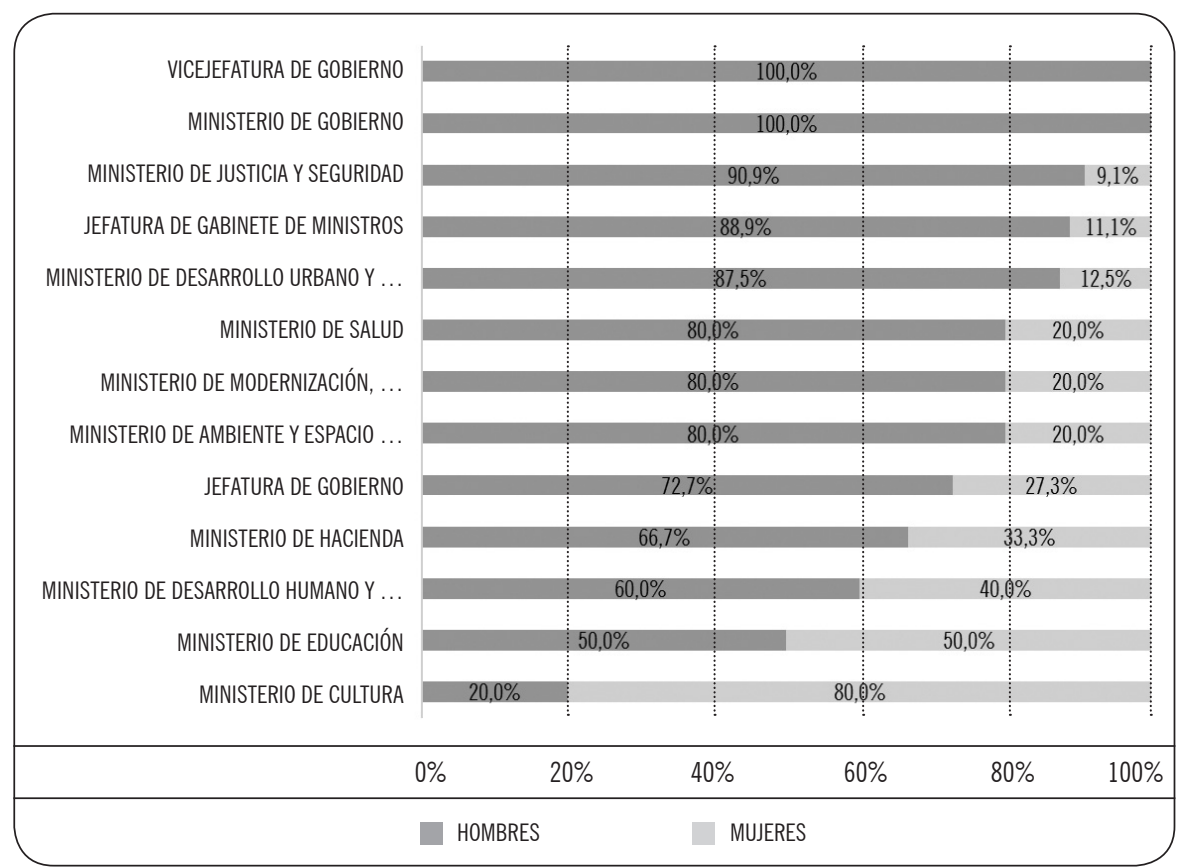

FUENTE: Observatorio de las Elites del CITRA (CONICET-UMET).

8] La Unidad de Coordinación de la Gobernación poseía solo una funcionaria integrando la cúpula, María Soledad Borsani, amiga personal de la gobernadora Vidal. 
Rodríguez Larreta confirmó esta tendencia. Como muestra el gráfico 6, con un promedio general de 23,8\% de mujeres, el Jefe de Gobierno de CABA no nombró funcionarias ni en las cúpulas de la Vicejefatura ni en las del Ministerio de Gobierno, y las mujeres «empataron» o superaron a los hombres solo en dos dependencias «tradicionalmente femeninas», como Educación (50\%) y Cultura (80\%).

Al comparar los cargos más altos (ministros/as) con los más bajos (subsecretarios/as) de los respectivos gabinetes, se observa que las mujeres tendieron a ocupar estos últimos (Gráficos 7, 8 y 9).

GRÁFICO 7:

TIPO DE CARGO DEL GABINETE DE NACIÓN, SEGÚN SEXO. N=350

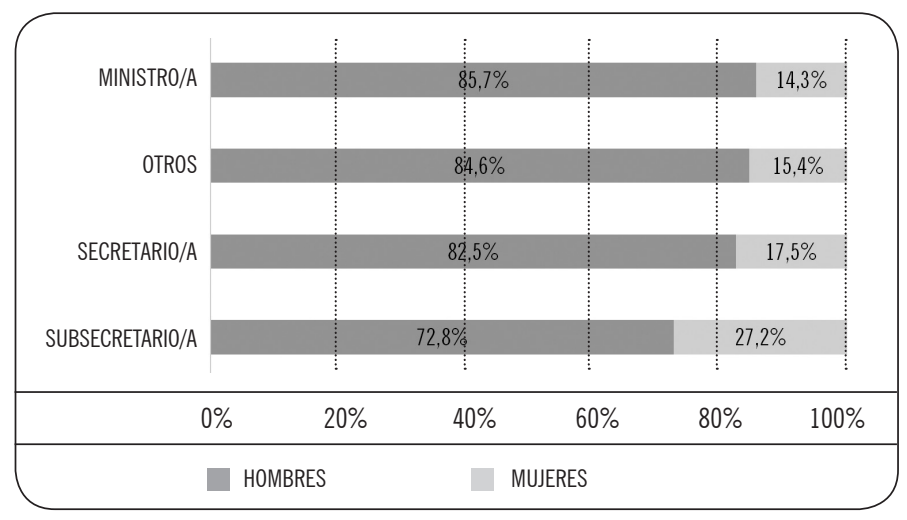

FUENTE: Observatorio de las Elites del CITRA (CONICET-UMET).

GRÁFICO 8:

TIPO DE CARGO DEL GABINETE DE PBA, SEGÚN SEXO. N=91

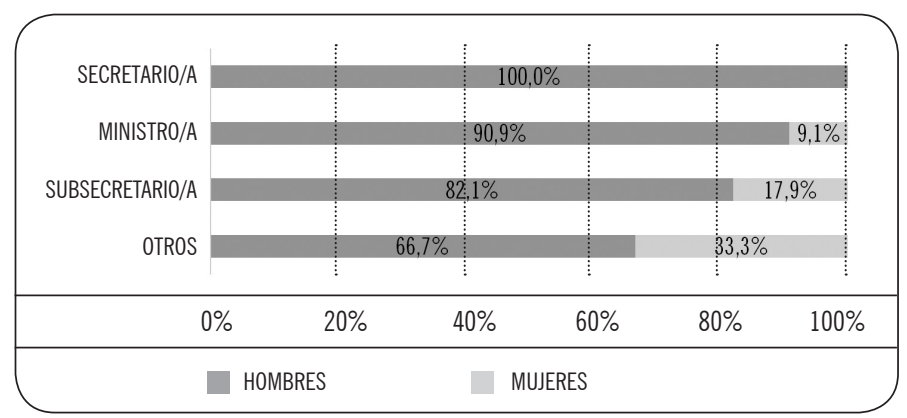


GRÁFICO 9:

TIPO DE CARGO DEL GABINETE DE CABA, SEGÚN SEXO. N=84

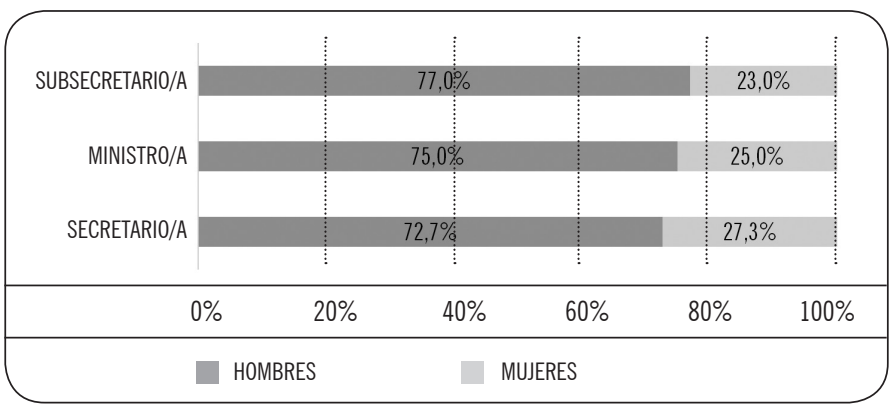

FUENTE: Observatorio de las Elites del CITRA (CONICET-UMET).

En el gabinete inicial de Macri, solo el I4,3\% de los ministros fueron mujeres, mientras que entre los subsecretarios esta proporción subió al 27,2\%. En el de Vidal, la relación es de 9,1\% a 17,9\%, respectivamente, y los cargos de secretario fueron entregados enteramente a hombres. En el caso de Rodríguez Larreta, los indicadores de género fueron levemente mejores: un $25 \%$ de ministras y un $23 \%$ de subsecretarias.

La desigualdad de género que presentan todas estas elites ejecutivas resulta aún más flagrante cuando se observa que las funcionarias mujeres tienden a tener credenciales educativas más elevadas que los funcionarios hombres, en las tres dependencias, como muestran los Gráficos IO, II y I2:

GRÁFICO 10:

MÁXIMO NIVEL EDUCATIVO ALCANZADO POR LOS FUNCIONARIOS DEL GABINETE DE NACIÓN SEGÚN SEXO. N=293

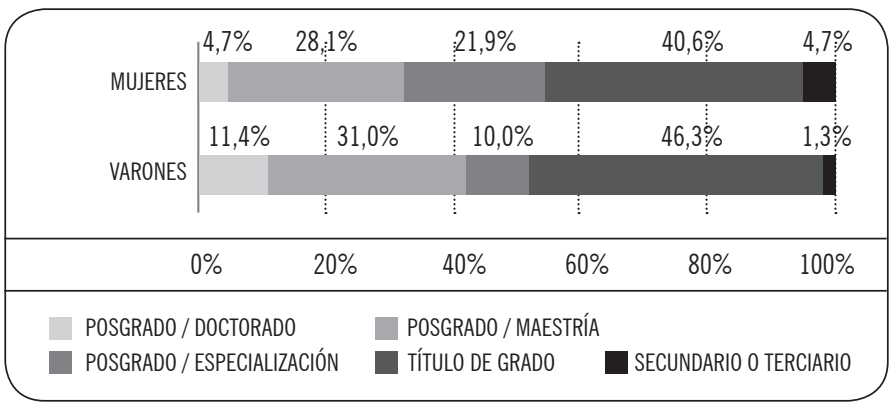

FUENTE: Observatorio de las Elites del CITRA (CONICET-UMET). 
GRÁFICO 11:

MÁXIMO NIVEL EDUCATIVO ALCANZADO POR LOS FUNCIONARIOS DEL GABINETE DE PBA SEGÚN SEXO. N=84

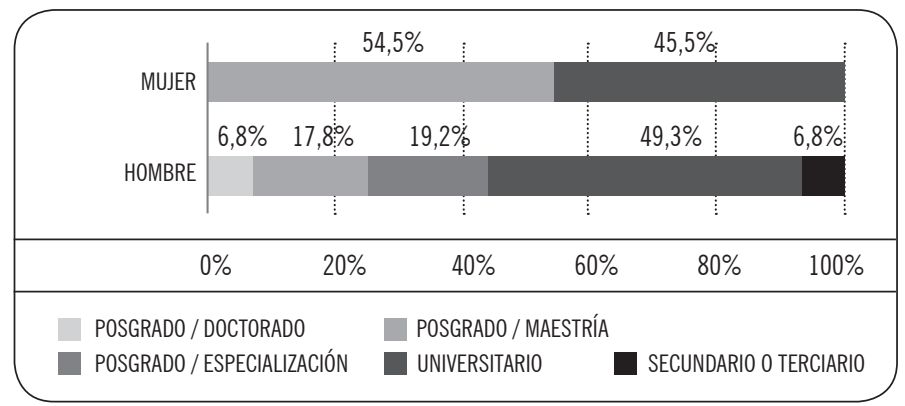

FUENTE: Observatorio de las Elites del CITRA (CONICET-UMET).

GRÁFICO 12:

MÁXIMO NIVEL EDUCATIVO ALCANZADO POR LOS FUNCIONARIOS DEL GABINETE DE CABA SEGÚN SEXO. N=70

\begin{tabular}{|c|c|c|c|c|c|}
\hline \multirow[b]{2}{*}{ MUJERES } & $5,3 \%$ & $31,6 \%$ & $31,6 \%$ & $23,6 \%$ & $5,3 \%$ \\
\hline & & & & & \\
\hline & $2,0 \%$ & $43,1 \%$ & $17,6 \%$ & $33: 3 \%$ & $3,9 \%$ \\
\hline VARONES & & & & & \\
\hline & $\%$ & $20 \%$ & $40 \%$ & $80 \%$ & $100 \%$ \\
\hline POSGRADO / D & DOCTOR & & OSGRADO / MAESTRÍA & & \\
\hline POSGRADO / ES & ESPECIA & ACIÓN & NIVERSITARIO & - SECUNDARIO 0 & TERCIARIO \\
\hline
\end{tabular}

FUENTE: Observatorio de las Elites del CITRA (CONICET-UMET).

Si se considera el máximo nivel educativo alcanzado por hombres y por mujeres en cada gabinete, se observa que en Nación un 54,7\% de las mujeres de la cúpula posee algún tipo de posgrado, contra un 52,4\% de los hombres. En PBA, la relación es de $54,5 \%$ contra $43,8 \%$ de hombres con misma titulación. Mientras que en CABA es de $68,5 \%$ contra $62,7 \%$, también en favor de las mujeres. 
GRÁFICO 13:

PROMEDIO DE EDAD EN CADA DEPENDENCIA DEL GABINETE DE NACIÓN. N=342

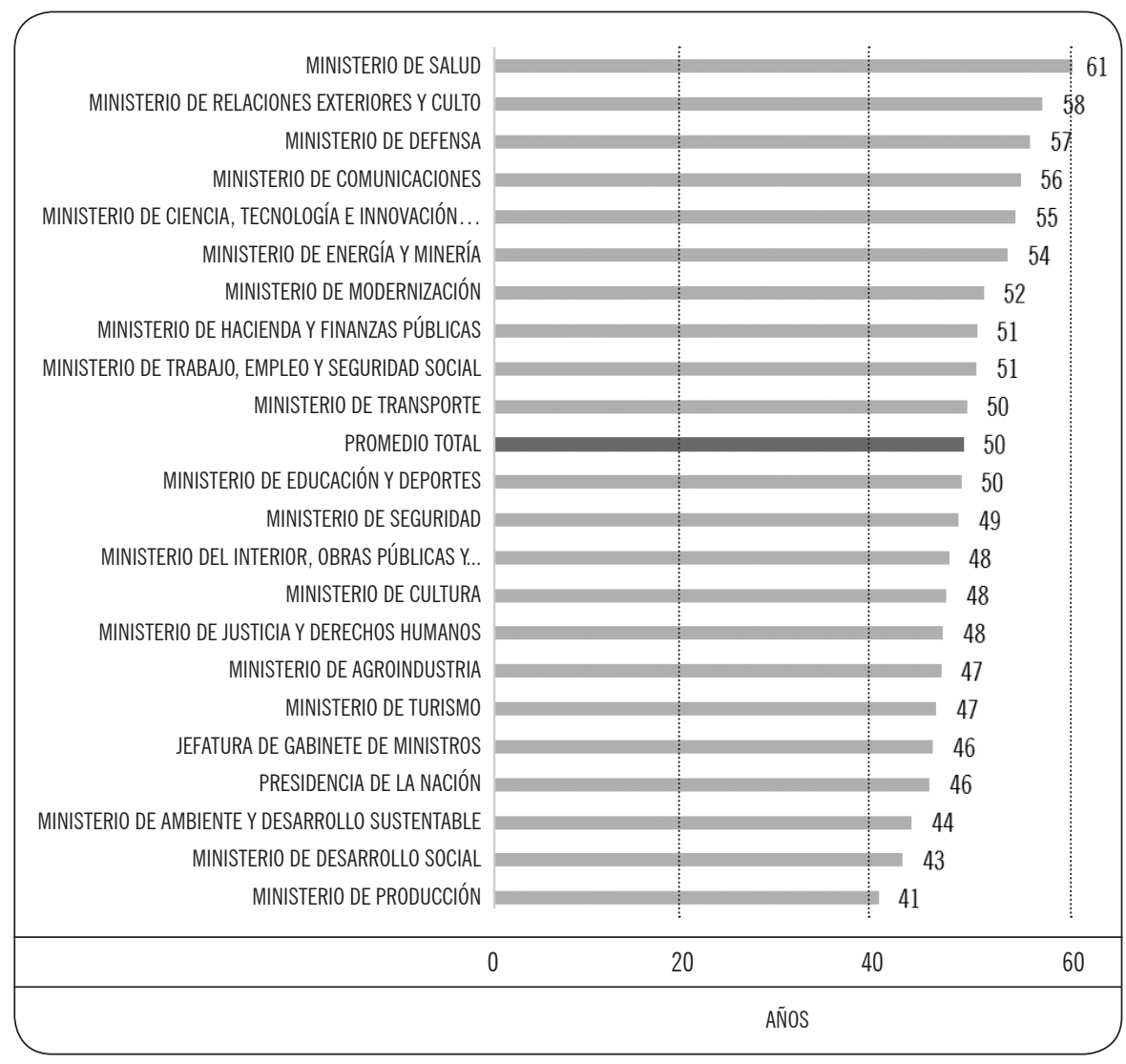

FUENTE: Observatorio de las Elites del CITRA (CONICET-UMET). 
GRÁFICO 14:

PROMEDIO DE EDAD EN CADA DEPENDENCIA DEL GABINETE DE PBA, POR DEPENDENCIA. $\mathrm{N}=91$.

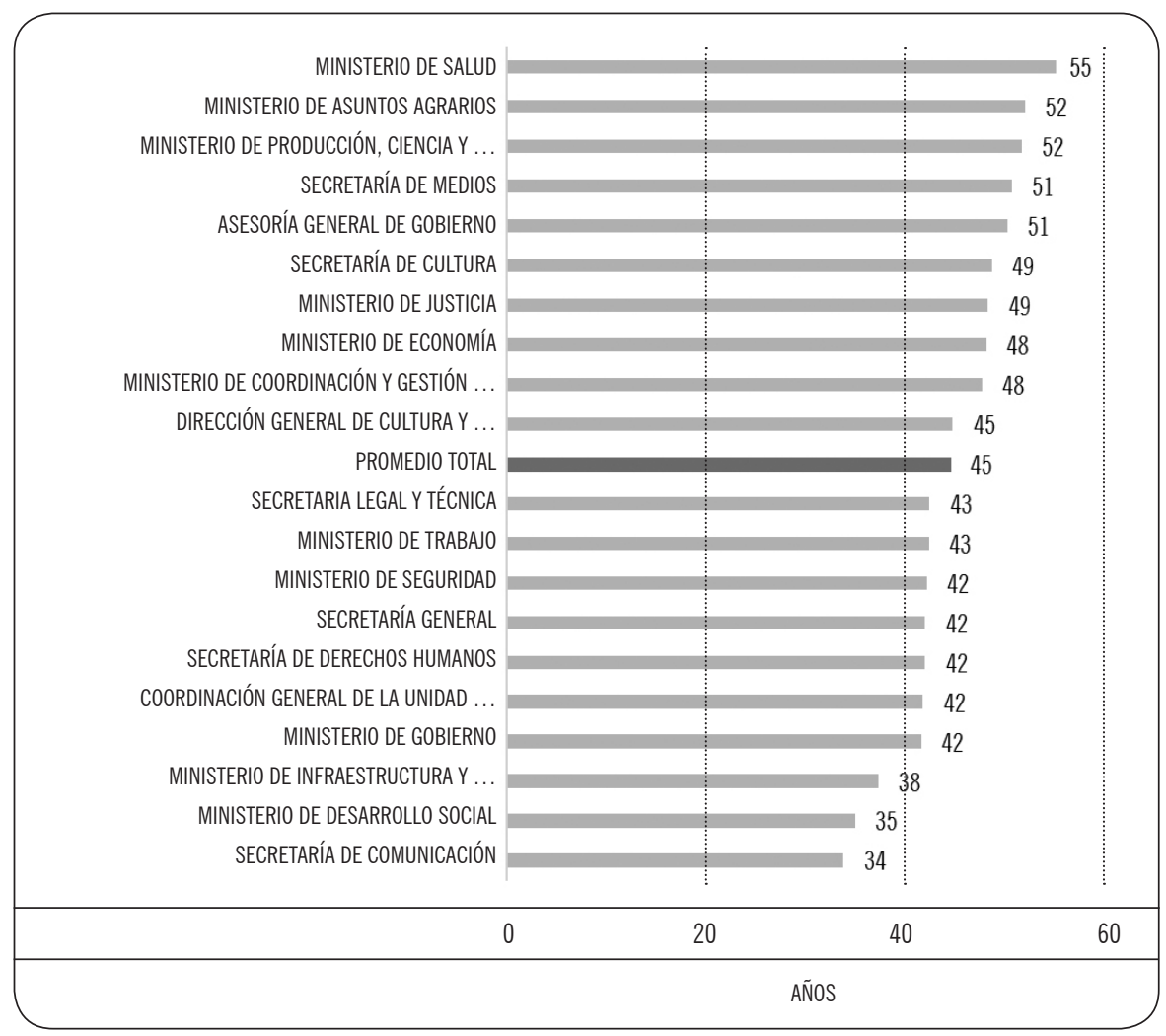

FUENTE: Observatorio de las Elites del CITRA (CONICET-UMET). 
GRÁFICO 15:

PROMEDIO DE EDAD EN CADA DEPENDENCIA DEL GABINETE DE CABA. $\mathrm{N}=76$.

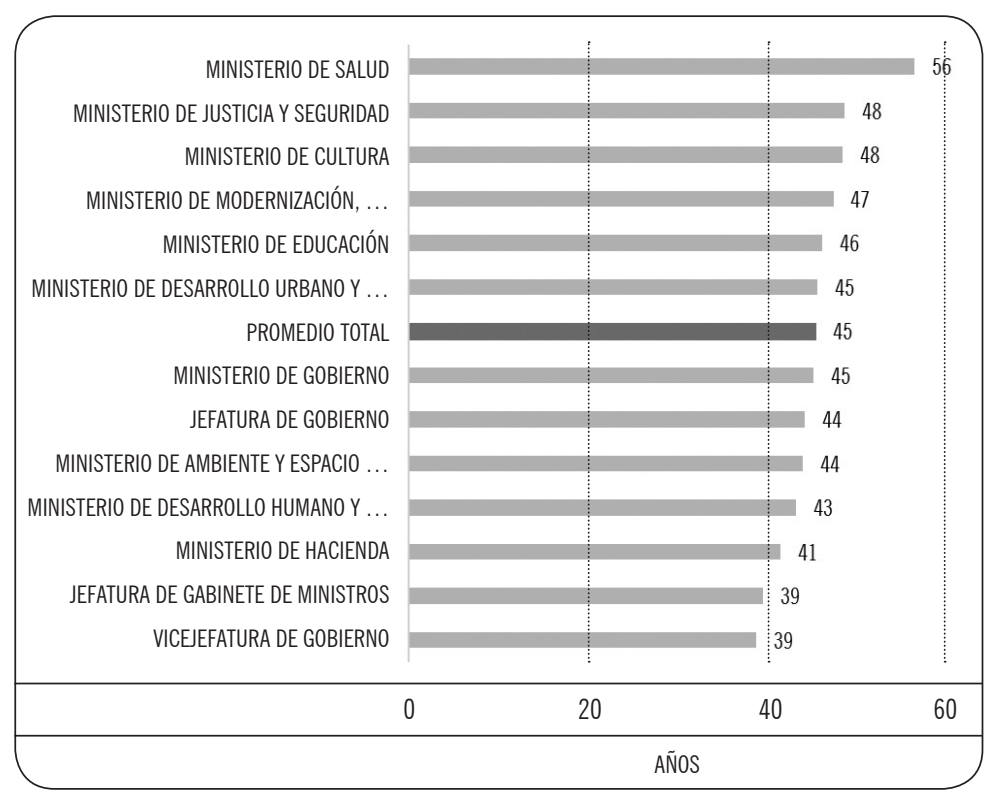

FUENTE:

Cuando se analiza la edad de los funcionarios (Gráficos I3, I4 y I5), se advierte que los equipos de Cambiemos estuvieron integrados por funcionarios relativamente jóvenes. El gabinete de Macri fue el más «viejo», con un promedio etario de 50 años, mientras que los de Vidal y Larreta mostraron el mismo promedio de edad, de 45 años promedio. En el gabinete de pвa se encuentran las 3 dependencias con promedios de edad más bajos: Infraestructura, Desarrollo Social y Comunicación, esta última con un promedio de solo 34 años. En los tres gabinetes, las cúpulas de Salud fueron las que presentaron edades más elevadas.

Es escasa la literatura que brinda parámetros de comparación de estos datos con los de otros gabinetes argentinos. Además, los estudios que incluyen observaciones sobre la edad de los funcionarios del gabinete se han dedicado solo a los ministros, sin incluir a secretarios o subsecretarios. Solo como referencia, en estos trabajos se identifica una tendencia al decrecimiento de la edad promedio con la que estas elites políticas acceden a sus posiciones. Por ejemplo, el conjunto de los ministros nacionales de la última dictadura argentina presentó un promedio de 
54 años de edad (CANElo, 20I6: 57-75); los ministros del presidente Raúl Alfonsín un promedio de 53 años, y los de Carlos Menem, 5I años. Si se considera a todos los ministros nacionales argentinos designados durante el período 1976-200I, la edad promedio fue de 53 años (CANelo, Castellani y heredia, 2OI5). Un estudio aún inédito que sí incluye a ministros, secretarios y subsecretarios de la segunda presidencia de Cristina Fernández de Kirchner muestra un promedio de poco menos de 50 años (CANELo y MARINo, 2020). Así, y salvando las distancias metodológicas entre todos estos estudios, el gabinete de Macri parece confirmar la tendencia histórica hacia el reclutamiento de ministros cada vez más jóvenes.

Por su parte, y a pesar de la ausencia de datos que permitan la comparación con otros niveles subnacionales, es posible aventurar que la baja edad de los equipos de PBA y de CABA puede haberse debido a motivos específicos y coyunturales. Es probable, por ejemplo, que Vidal, que al momento de asumir tenía solo 42 años, haya designado funcionarios no demasiado mayores que ella para fortalecer su autoridad (CANELO Y LASCURAIN, 20I7). Y cabe recordar que Horacio Rodríguez Larreta debió «exportar» en 2015 a gran parte de sus funcionarios hacia Nación y provincia (el 55,7\% del gabinete de Nación y el 69,4\% de PBA venía de CABA), lo que puede haber provocado la promoción de una generación relativamente más joven a las altas esferas de la CABA.

\section{PERFIL EDUCATIVO}

GRÁFICO 16:

MÁXIMO NIVEL EDUCATIVO ALCANZADO POR LOS FUNCIONARIOS DEL GABINETE DE NACIÓN. N=293.

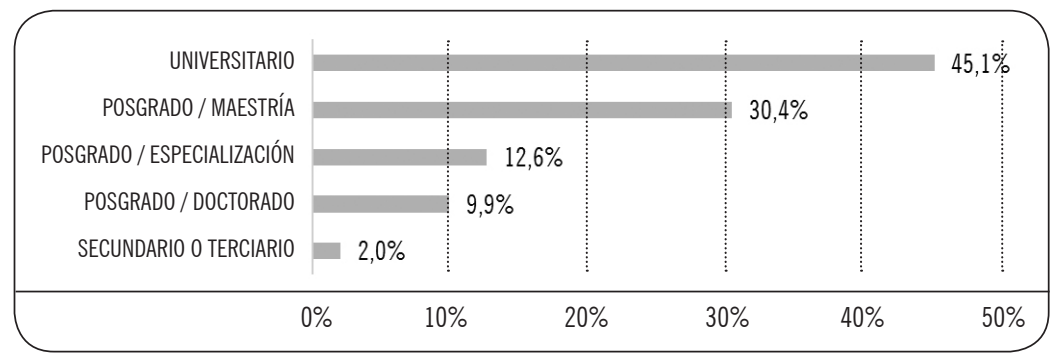

FUENTE: Observatorio de las Elites del CITRA (CONICET-UMET). 
GRÁFICO 17:

MÁXIMO NIVEL EDUCATIVO ALCANZADO POR LOS FUNCIONARIOS DEL GABINETE DE PBA. N=84

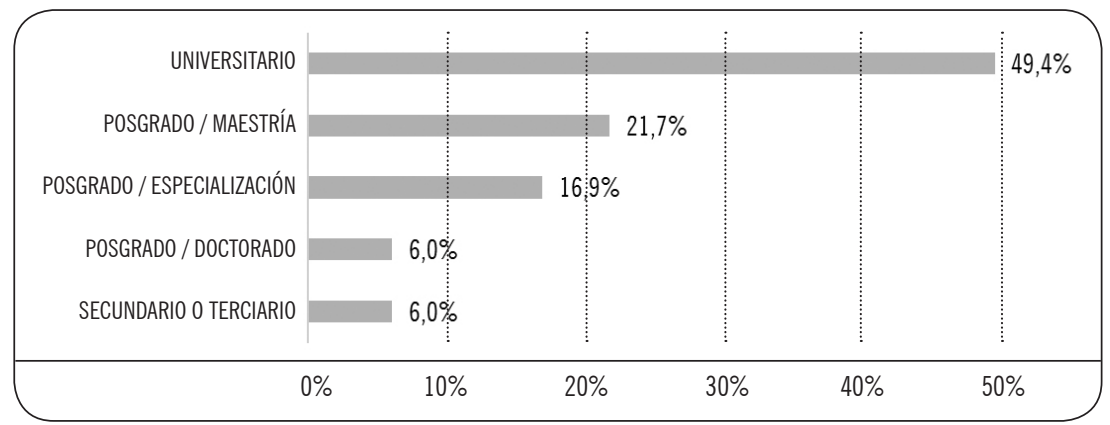

FUENTE: Observatorio de las Elites del CITRA (CONICET-UMET).

GRÁFICO 18:

MÁXIMO NIVEL EDUCATIVO ALCANZADO POR LOS FUNCIONARIOS DEL GABINETE DE CABA. N=70.

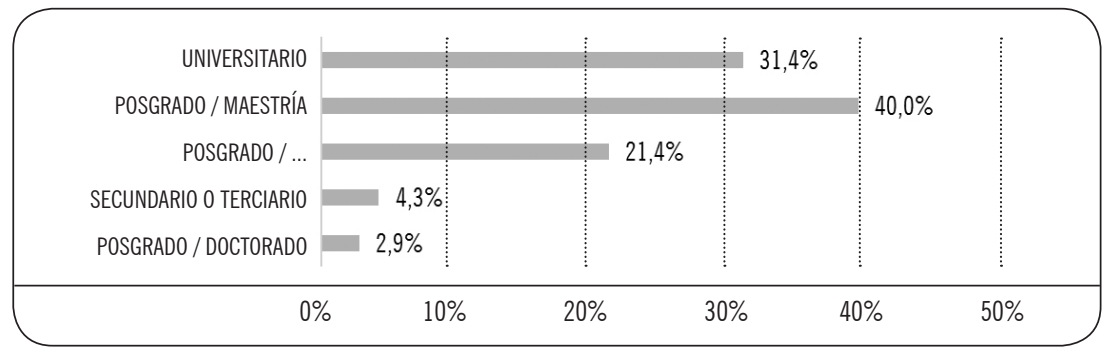

FUENTE: Observatorio de las Elites del CITRA (CONICET-UMET).

Los equipos de Cambiemos presentaron un alto nivel educativo general: como muestran los Gráficos I6, I7 y i $8^{9}$, en los tres gabinetes, entre el 94\% y el 98\% tenía nivel universitario completo o más. Este alto nivel contrasta fuertemente con el

9] Los Gráficos 16, 17 y 18 indican el máximo nivel educativo alcanzado por cada funcionario. Quienes están agrupados en «universitario» solo terminaron ese nivel y no completaron el posgrado. Y quienes están agrupados en cualquiera de las categorías de «posgrado» tienen, además, un título universitario. 
resto de la sociedad argentina (en 2018 , solo un $22,3 \%$ de las mujeres y un $17,4 \%$ de los hombres mayores de 23 años tenía título universitario (OBSERVATORIO NACIONAL DE VIOLENCIA CONTRA LAS MUJERES, 20I8), pero es un rasgo histórico característico de las elites argentinas. Por ejemplo, entre 1976 y 200I, el 70\% del conjunto de la elite argentina poseía educación universitaria completa, y la mayoría había asistido a un establecimiento público (84\%) (CANELO, CASTELlani Y HEREDia, 2OI5).

El gabinete de CABA presentó un perfil «más instruido» que los de Nación у РвA: los funcionarios con alguna formación no solo de grado, sino también de posgrado (especialización, maestría o doctorado) representaron el 64,3\% del gabinete de Rodríguez Larreta. El gabinete de Vidal fue, comparativamente, el «menos educado»: solo el 44,6\% tuvo posgrado y se advierte mayor presencia de funcionarios que solo terminaron estudios secundarios (6\%).

Ha sido señalado por otros estudios sociológicos que la elite argentina, puntualmente la elite política, tendió a formarse en determinadas disciplinas consideradas tradicionalmente como las «llaves que abren todas las puertas»: éstas fueron abogacía, medicina, ingeniería, y más adelante ciencias económicas, en general cursadas en establecimientos públicos; a ellas se sumó también la formación militar, apreciada durante varias décadas por sus perspectivas de ascenso social (DE IMAZ, 1964), pero que desaparece de las preferencias de las elites después de la última dictadura (CANELO, CASTELLANI Y HEREDIA, 20I5).

CUADRO 1:

TIPO DE TÍTULO DE GRADO, POR GABINETE (EN \%)

\begin{tabular}{|l|c|l|l|l|l|l|l|}
\hline GABINETE & $\begin{array}{l}\text { DERECHO } \\
\text { Y CIENCIAS } \\
\text { JURÍDICAS }\end{array}$ & $\begin{array}{l}\text { CIENCIAS } \\
\text { ECONÓMICAS } \\
\text { / EMPRESA- } \\
\text { RIALES }\end{array}$ & $\begin{array}{l}\text { INGE- } \\
\text { NIERÍAS } \\
\text { VARIAS }\end{array}$ & $\begin{array}{l}\text { CIENCIAS } \\
\text { MÉDICAS } \\
\text { Y DE LA } \\
\text { SALUD }\end{array}$ & $\begin{array}{l}\text { CIENCIAS } \\
\text { POLIIICAS, RRII, } \\
\text { ADMINISTRA- } \\
\text { CIÓN PÚBLICA }\end{array}$ & $\begin{array}{l}\text { OTRAS } \\
\text { CIENCIAS } \\
\text { SOCIALES Y } \\
\text { HUMANAS }\end{array}$ & $\begin{array}{l}\text { OTRAS } \\
\text { DISCIPLINAS }\end{array}$ \\
\hline NACIÓN (N=283) & 27,9 & 27,2 & 16,6 & 3,5 & 11 & 6 & 7,8 \\
PBA (N=79) & 35,4 & 19 & 10,1 & 5,1 & 15,2 & 10,1 & 5,1 \\
CABA (N=66) & 28,1 & 26,6 & 3,1 & 7,8 & 18,8 & 7,8 & 7,8 \\
\hline
\end{tabular}

FUENTE: Observatorio de las Elites del CITRA (CONICET-UMET). 
El Cuadro I muestra que Macri (ingeniero), Vidal (politóloga) y Rodríguez Larreta (economista) eligieron funcionarios formados, en general, en disciplinas tradicionales. Las disciplinas de grado que pueden ser agrupadas dentro de la categoría derecho y ciencias jurídicas representaron el 75,2\% en Nación, el 69,6\% en PBA y el $65,6 \%$ en CABA.

Este perfil educativo de tipo tradicional se combina con una novedad: un importante peso de los funcionarios formados en ciencias políticas, relaciones internacionales y administración pública, disciplinas con baja representación en la educación tradicional de las élites argentinas. Por ejemplo, en el gabinete $20 I I$ de Fernández de Kirchner estas disciplinas no superaban el 8\% (CANELO y MARINO, 2020). Este rasgo, importante en CABA (I8,8\%) y en PBA ( $15,2 \%)$, muestra que con Cambiemos llegó al gobierno una élite con un perfil educativo específico, donde los diplomados en disciplinas tradicionales se mezclan con lo que hemos llamado «especialistas en gestión estatal» (CANELO, 2019), una elite formada en el manejo de lo público-estatal. También se advierte en estos equipos la presencia de funcionarios educados en otras ciencias sociales y humanas, que por ejemplo en el gabinete de Vidal alcanzó un IO\%.

Cuando se observa el nivel de posgrado (especializaciones, maestrías o doctorados) se profundiza la presencia de «especialistas en gestión estatal» (Cuadro 2):

CUADRO 2:

TIPO DE TÍTULO DE POSGRADO, POR GABINETE (EN\%)

\begin{tabular}{|l|c|l|c|c|l|l|c|}
\hline GABINETE & $\begin{array}{l}\text { DERECHO } \\
\text { Y CIENCIAS } \\
\text { JURÍDICAS }\end{array}$ & $\begin{array}{l}\text { CIENCIAS } \\
\text { ECONÓMICAS } \\
\text { / EMPRESA- } \\
\text { RIALES }\end{array}$ & $\begin{array}{l}\text { INGE- } \\
\text { NIERÍAS } \\
\text { VARIAS }\end{array}$ & $\begin{array}{l}\text { CIENCIAS } \\
\text { MÉDICAS } \\
\text { Y DE LA } \\
\text { SALUD }\end{array}$ & $\begin{array}{l}\text { CIENCIAS } \\
\text { POLIIICAS, RRII, } \\
\text { ADMINISTRA- } \\
\text { CIÓN PÚBLICA }\end{array}$ & $\begin{array}{l}\text { OTRAS } \\
\text { CIENCIAS } \\
\text { SOCIALES Y } \\
\text { HUMANAS }\end{array}$ & $\begin{array}{l}\text { OTRAS } \\
\text { DISCIPLINAS }\end{array}$ \\
\hline NACIÓN (155 CASOS) & 13,5 & 38,7 & 5,2 & 1,3 & 27,1 & 5,2 & 9 \\
PBA (38 CASOS) & 18,4 & 29 & - & 10,5 & 34,2 & 7,9 & - \\
CABA (71 CASOS) & 12,5 & 31,3 & - & 2,1 & $39,6 \%$ & 6,3 & 8,3 \\
\hline
\end{tabular}

FUENTE: Observatorio de las Elites del CITRA (CONICET-UMET). 
Los «especialistas en gestión estatal» se distribuyeron desigualmente en los gabinetes. En Nación están presentes en la mayoría de las carteras, pero se agrupan en los ministerios de Cultura, Jefatura de Gabinete, Producción y Turismo, y Modernización. En PBA se concentran en dependencias cercanas a la gobernadora, también politóloga: la Secretaría de Comunicación, el Ministerio de Gobierno y la Secretaría General. En CABA estos «especialistas en gestión estatal» predominaron en el Ministerio de Desarrollo Humano y Hábitat, el Ministerio de Cultura, la Jefatura y Vicejefatura de Gobierno, y el Ministerio de Educación.

Puede afirmarse que, en general, la posesión de un título de posgrado es una variable importante a la hora de ocupar posiciones más altas en el gabinete. Sin embargo, no en todos los casos los ministros son más «educados» que los secretarios o subsecretarios. En Nación hay un $47,6 \%$ de ministros, contra un 50,6\% de secretarios y un $52,6 \%$ de subsecretarios con posgrado, lo que refuerza la naturaleza del cargo de ministro como un cargo más político que técnico. En PBA y CABA, sin embargo, se observa más asociación entre mayor nivel educativo y cargo más alto en el gabinete: hay un $63,7 \%$ de ministros, contra $28,6 \%$ de secretarios y $42,6 \%$ de subsecretarios con posgrado; en CABA, esta proporción es de $90 \%-37,5 \%-63,4 \%$.

Se mencionó más arriba que históricamente las elites argentinas tendieron a formarse en universidades públicas. Los equipos de Cambiemos mantienen esta tendencia general: el 67,5\% del equipo de Nación, el 63,4\% del de PBA y el 54,9\% del de CABA aprobaron sus estudios de grado en universidades públicas.

Sin embargo, también es cierto que Cambiemos prefirió, en mayor medida que otros gobiernos, a funcionarios educados en universidades privadas. Esto puede explicarse tanto por el crecimiento de la oferta educativa privada como por una preferencia específica de esta fuerza política, vinculada con el origen social alto o medio-alto de gran parte de sus miembros. Solo como referencia, y con las previsiones metodológicas ya realizadas, entre los ministros elegidos por Menem y De la Rúa solo el I8,5\% se había formado en universidades privadas (CANELO, CASTELLANI Y HEREDIA, 20I5), porcentaje similar al que alcanzaron los ministros, secretarios y subsecretarios del gabinete 201 i de Fernández de Kirchner (I7,8\%) (CANElo Y MARINO, 2020). Mientras que en los gabinetes de Cambiemos el porcentaje de funcionarios formados en universidades privadas ascendió al 30\% en Nación y PBA, y trepó al 43,7\% entre los funcionarios de Rodríguez Larreta (en este último caso, además, con predominio de las universidades privadas religiosas sobre las laicas). 
Los datos muestran un perfil educativo específico de los gabinetes de Cambiemos: especialización en disciplinas de gestión/administración estatal, y preferencia por la educación privada. Este perfil se profundiza a medida que avanza la trayectoria educativa de los funcionarios.

En efecto, a nivel de posgrado se reduce el peso de la formación tradicional al $58,7 \%$ en Nación, el 57,9\% en PBA y el 45,9\% en CABA. Los posgrados en ciencia política, relaciones internacionales y/o administración pública aumentan al 27,I\% en Nación, al 34,2\% en provincia y alcanzan un peso decisivo en la ciudad: casi el $40 \%$ del equipo de Larreta se especializó en estas disciplinas. También crece la preferencia por las universidades privadas sobre las públicas: en Nación, el 46,8\% de los funcionarios con posgrado lo hizo en una universidad privada, porcentaje que crece en $\mathrm{PBA}(58,3 \%)$ y en $\mathrm{CABA}(58,4 \%)$. Vale mencionar un último rasgo del perfil educativo particular de Cambiemos: la preferencia de posgrados en establecimientos extranjeros, que se aproxima al 30\% en los tres gabinetes, rasgo probablemente vinculado con el origen empresarial de varios funcionarios.

\section{PARTICIPACION EN FUNDACIONES Y PARTIDOS POLÍTICOS}

Como se mencionó, uno de los elementos centrales de la narrativa de Cambiemos fue la de «nueva generación», y la de supuesta ajenidad con el mundo «corrupto» $\mathrm{y}$ "prebendario» de «la política». Su procedencia de los sectores altos o medios altos de la sociedad argentina, y/o del mundo del voluntariado, del «onegeísmo» y las fundaciones (BELLOTTI, MORRESI Y VOMMARO, 2OI5; VOMMARO Y MORRESI, 20I5), atributos extensamente «señalizados» por Cambiemos (CANELO, 2OI9), llevó a que el «meterse en política» de este alto funcionariado fuese presentado como un acontecimiento sacrificial y vocacional.

Sin embargo, una mirada atenta sobre las trayectorias de los funcionarios de Macri, Vidal y Larreta permite matizar esta ajenidad con el mundo de «la política». Los datos muestran que la pertenencia a fundaciones y ONG es un rasgo constitu- 
tivo de este personal político, pero que también lo es la participación en política partidaria ${ }^{10}$. Y no solo en las fuerzas que componen la coalición de gobierno sino también, por ejemplo, en el peronismo.

CUADRO 3:

PARTICIPACIÓN DE LOS FUNCIONARIOS DE NACIÓN, PBA Y CABA EN ONG Y FUNDACIONES, Y PARTIDOS POLĹTICOS

\begin{tabular}{|l|l|l|}
\hline GABINETE & $\begin{array}{l}\text { PARTIIIPACIÓN } \\
\text { EN ONG Y FUNDACIONES } \\
\text { (\% SOBRE TOTAL DEL GABINETE) }\end{array}$ & $\begin{array}{l}\text { PARTICIPACIÓN } \\
\text { EN PARTIDOS POLÍTICOS } \\
\text { (\% SOBRE TOTAL DEL GABINETE) }\end{array}$ \\
\hline NACIÓN & 44,3 & 17,1 \\
PBA & 35,2 & 44 \\
CABA & 44 & 16,7 \\
\hline
\end{tabular}

FUENTE: Observatorio de las Elites del CITRA (CONICET-UMET).

Los tres gabinetes, en especial los de Macri y Rodríguez Larreta, están estrechamente vinculados con el mundo del onegeísmo. En este último caso, sin dudas, que el jefe de Gobierno de caba haya sido el creador del Grupo Sophia fue determinante en la composición de sus equipos de gobierno.

Los funcionarios onegeístas se distribuyeron disparmente en los gabinetes. Aquellos vinculados con las fundaciones y ONG más cercanos al PRO (Fundación Creer y Crecer, Grupo Sophia, Fundación Pensar) estuvieron presentes en todas las dependencias de Nación, pero colonizaron especialmente el Ministerio de Justicia y Derechos Humanos, el de Agroindustria, el de Trabajo, Empleo y Seguridad Social, el de Producción, y el de Desarrollo Social. En Pba se concentraron en los ministerios de Coordinación y Gestión Pública, en Asuntos Agrarios, Seguridad, e

10] Como advierte gran parte de la bibliografía sobre elites políticas, el dato sobre participación en partidos políticos es difícil de construir. Aquí consideramos una definición estricta, la de afiliación concreta de un individuo a un partido político y/o la competencia por (o la ocupación de) cargos electivos, al menos una vez en el transcurso de su trayectoria. En caso de haber registrado dos datos de participaciones del mismo individuo en fuerzas diferentes, presentamos el más reciente: esto puede haber subrepresentado la participación política de estos funcionarios pero no deja de confirmar nuestro argumento. 
Infraestructura y Servicios Públicos. En CaBA este perfil de funcionario onegeísta se ubicó en el Ministerio de Desarrollo Urbano y Transporte, Educación, la Jefatura de Gabinete de Ministros, y Desarrollo Humano y Habitat.

Al observar la participación en partidos políticos se observa que la mayoría del personal político de estos gabinetes provino del PRO o la UCR, los aliados principales de la coalición, como muestran los Gráficos 19, 20 y 2I:

GRÁFICO 19:

PARTIDOS POLÍTICOS EN QUE PARTICIPAN/PARTICIPARON LOS FUNCIONARIOS DEL GABINETE DE NACIÓN. N=59.

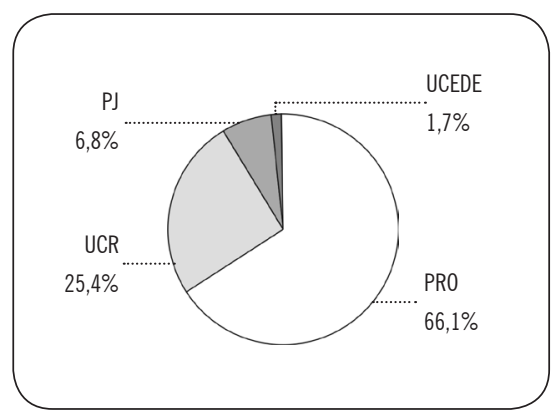

GRÁFICO 21:

PARTIDOS POLIITICOS EN QUE PARTICIPAN/PARTIIIPARON LOS FUNCIONARIOS DEL GABINETE DE CABA. N=14.

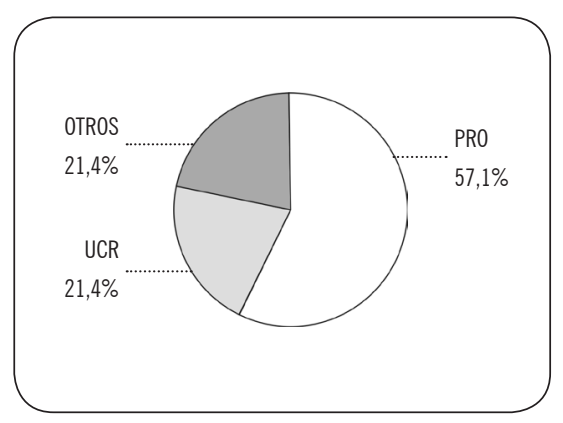

GRÁFICO 20:

PARTIDOS POLÍTICOS EN QUE PARTICIPAN/PARTIIIPARON LOS FUNCIONARIOS DEL GABINETE DE PBA. N=40.

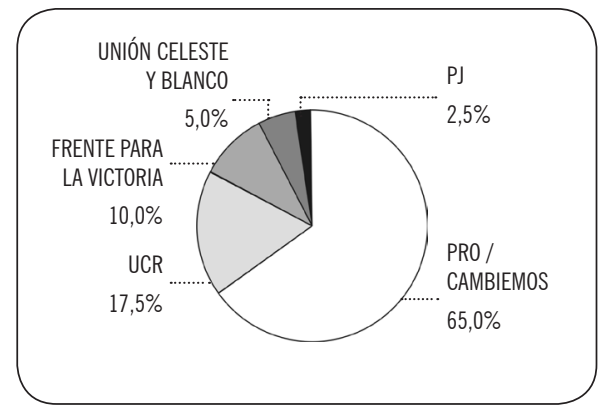

FUENTE (GRÁFICOS 19 A 21):

Observatorio de las Elites del CITRA (CONICET-UMET). 
Pero los datos muestran otros datos significativos. Primero, se advierte el alto grado de participación político-partidaria que presentó el equipo de Vidal, con un $44 \%$, lo que muestra que la gobernadora tendió a reclutar funcionarios con experiencia en política con mucho más énfasis que sus pares de Nación y CABA, conformando un verdadero "gabinete político" para gobernar uno de los territorios más conflictivos de la Argentina (CANELO y LASCURAIN, 20I7).

Segundo, los datos muestran que aunque el pro fue, en todos los casos, la fuerza mayoritaria (alrededor del 60\%), seguido en general por la UCR, Vidal designó en PBA un equipo multipartidario, donde encontramos incluso una importante "pata peronista» (17,5\%) y donde la UCR estuvo subrepresentada. A pesar de que el PRo controló casi la mitad del gabinete de Vidal, esta "pata peronista» tuvo una importante participación en áreas como el Ministerio de Desarrollo Social, el Ministerio de Producción, Ciencia y Tecnología, y especialmente la Asesoría general de Gobierno y el Ministerio de Asuntos Agrarios (Gráfico 22).

Así, los datos sugieren que la gobernadora de la provincia de Buenos Aires desplegó criterios de reclutamiento diferentes a los de Macri y Rodríguez Larreta, con el objetivo de construir un gabinete experimentado políticamente, y capaz de construir alianzas con diversos actores sociales y políticos en el conflictivo territorio bonaerense.

Un tercer rasgo que surge del análisis de la participación político-partidaria de los funcionarios de Cambiemos es que los mismos no fueron designados necesariamente en las áreas políticas. Este es un rasgo que distingue al gabinete de Nación de los otros dos: los funcionarios con experiencia en política fueron asignados por Macri a los Ministerios de Agroindustria, Trabajo, Empleo y Seguridad Social, y a las Secretarías de la Presidencia, mientras que, como se verá, las areas politicas fueron ocupadas por CEO.

En PBA y CABA se advierte, sí, una mayor adecuación entre participación político-partidaria y designación en áreas políticas. En el gabinete de Vidal, este perfil de funcionario fue designado en los ministerios de Agricultura y Servicios Públicos, Seguridad, Gobierno, Desarrollo Social, y en la Asesoría General de Gobierno. En CABA se concentran en el Ministerio de Justicia y Seguridad, y con menor intensidad en Desarrollo Humano y Habitat, Cultura, la Jefatura de Gobierno y la Jefatura de Gabinete de Ministros. 
GRÁFICO 22:

GABINETE DE PBA. FUNCIONARIOS QUE PARTICIPAN/PARTICIPARON EN PARTIDOS POLÍTICOS POR DEPENDENCIA. N=40

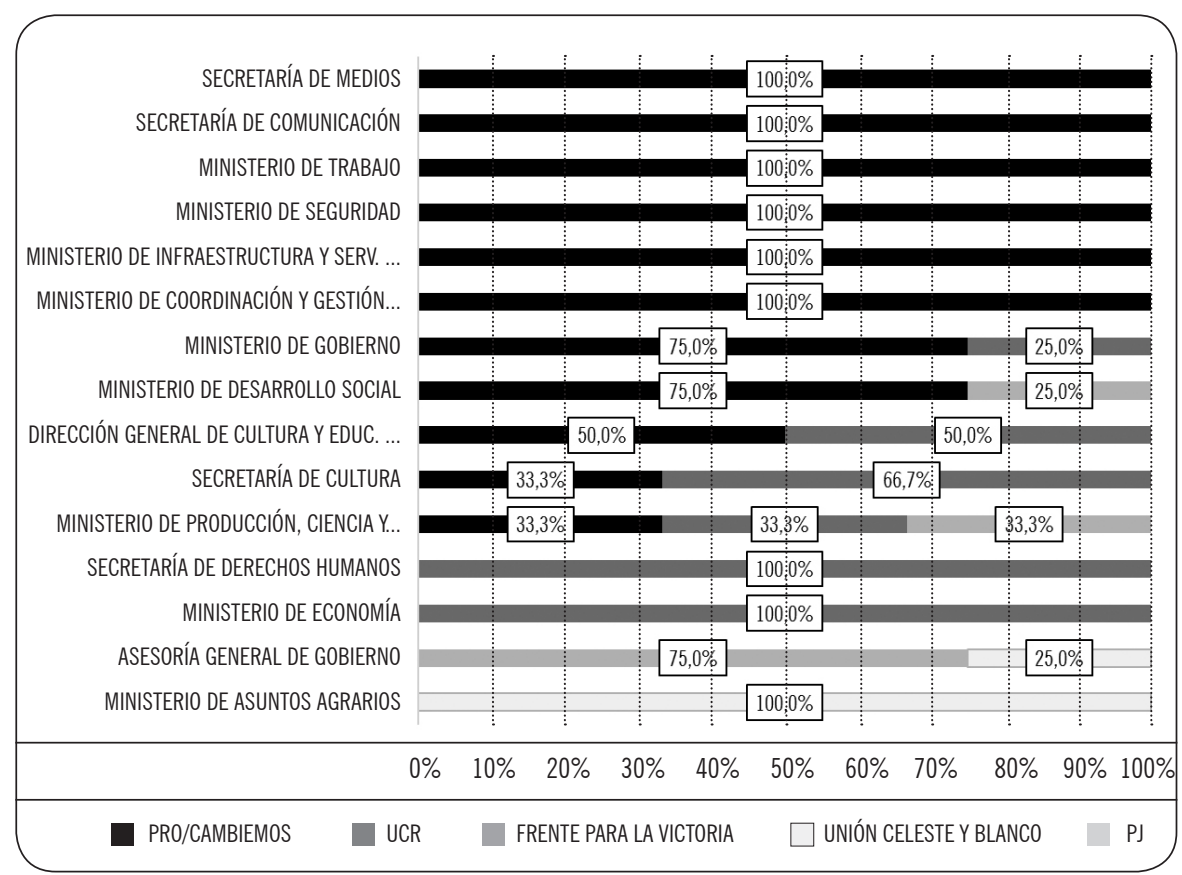

FUENTE: Observatorio de las Elites del CITRA (CONICET-UMET). 


\section{PERFIL OCUPACIONAL}

Aunque el de Cambiemos no haya sido el primer gobierno de la historia argentina en recurrir a hombres de empresa para formar sus equipos, su presencia nunca fue tan visible, ni estuvo tan extendida, ni incluyó también áreas «extraeconómicas», como sucedió entre 2015 y 2019 (CANELO y CASTELLANI, 2OI7).

Como muestran los Gráficos 23, 24 y 25, el peso de los CEO fue importante en los tres gabinetes: un 30,6\% promedio en el de Macri, un 28,6\% en el de Vidal y un $27,4 \%$ en el de Larreta.

GRÁFICO 23:

PORCENTAJE DE CEO EN CADA DEPENDENCIA DEL GABINETE DE NACIÓN. N=350.

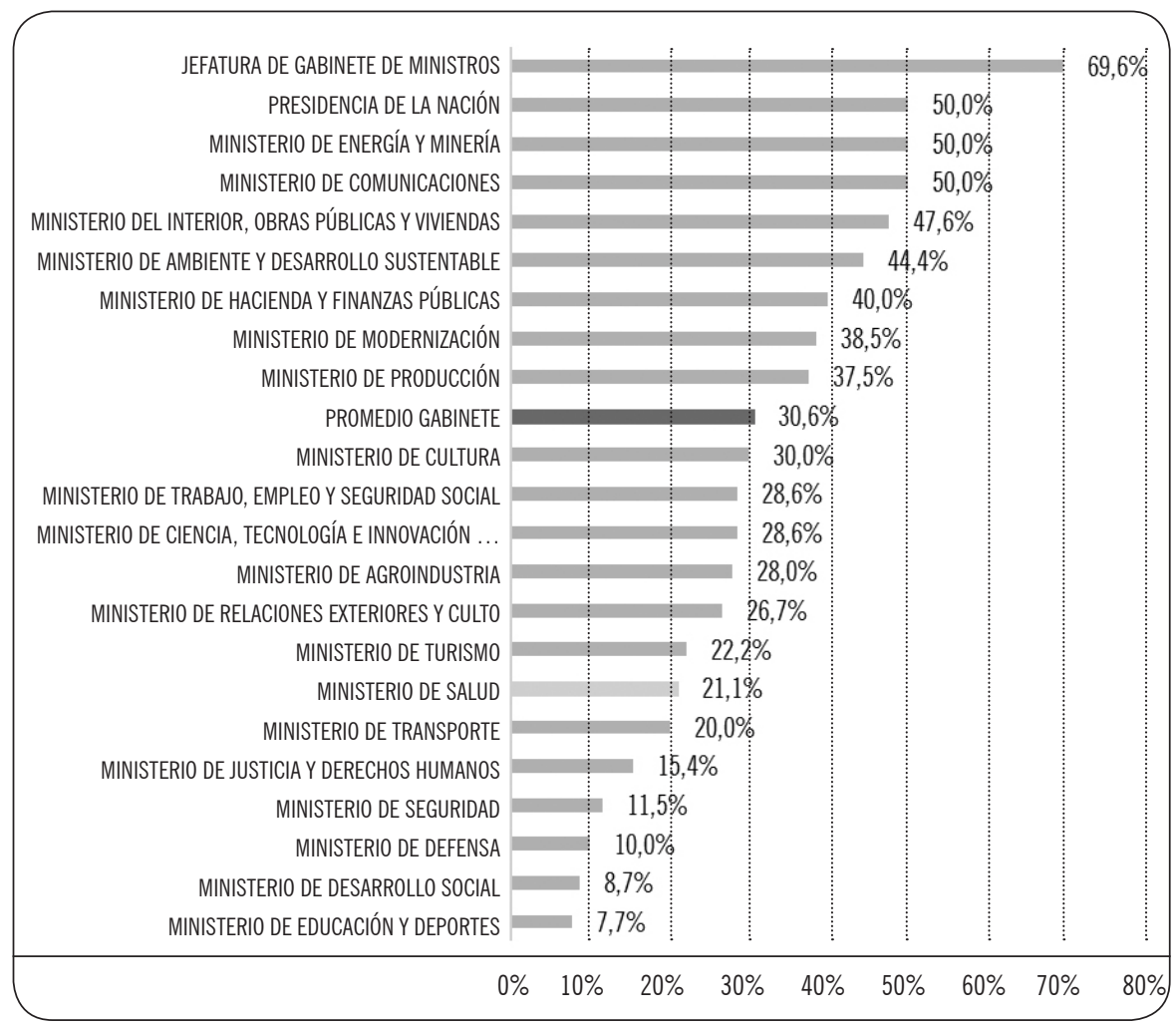

FUENTE: Observatorio de las Elites del CITRA (CONICET-UMET). 
PORCENTAJE DE CEO EN CADA DEPENDENCIA DEL GABINETE DE PBA. $\mathrm{N}=91$.

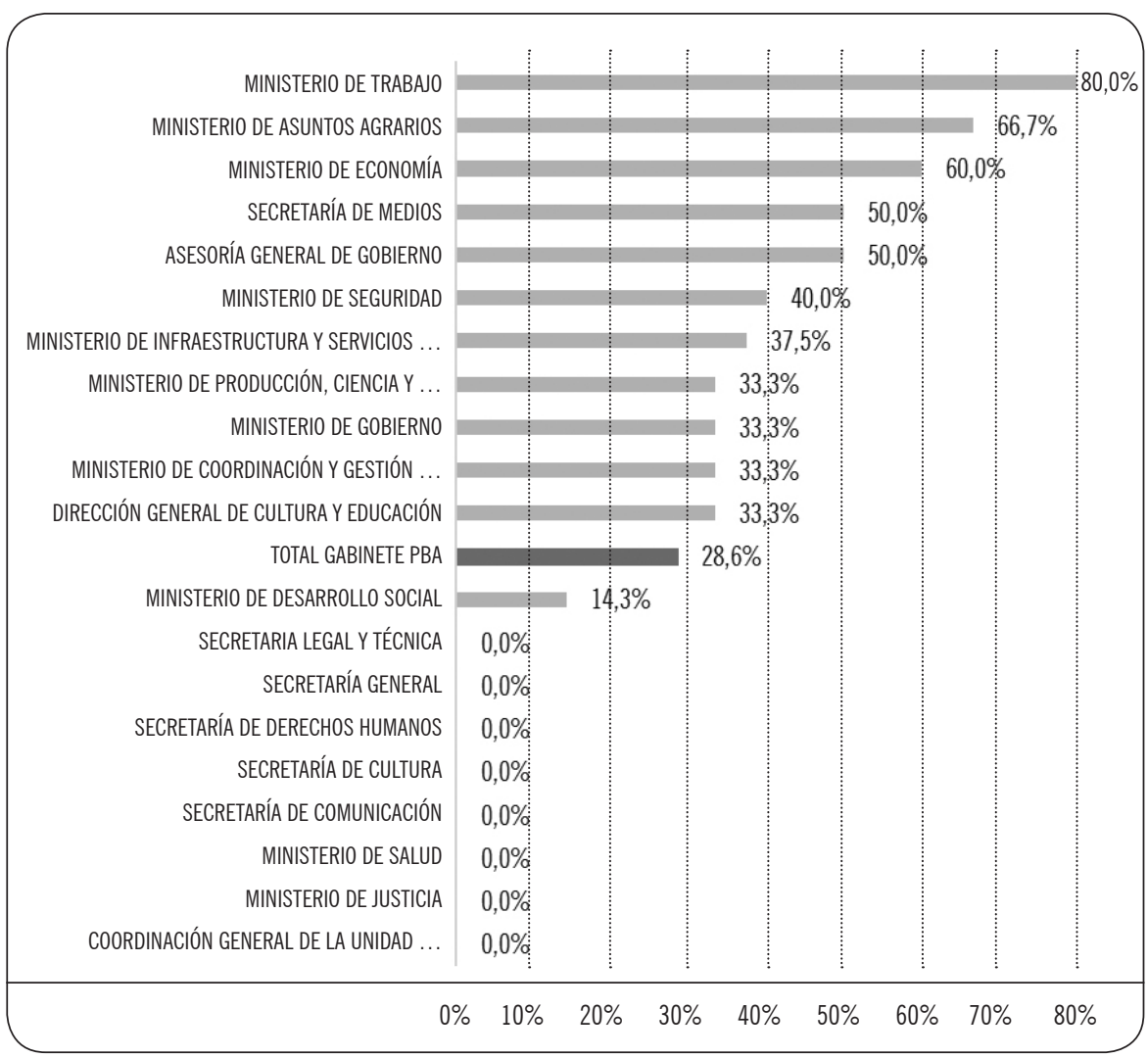

FUENTE: Observatorio de las Elites del CITRA (CONICET-UMET). 
GRÁFICO 25:

PORCENTAJE DE CEO EN CADA DEPENDENCIA DEL GABINETE DE CABA. $\mathrm{N}=84$.

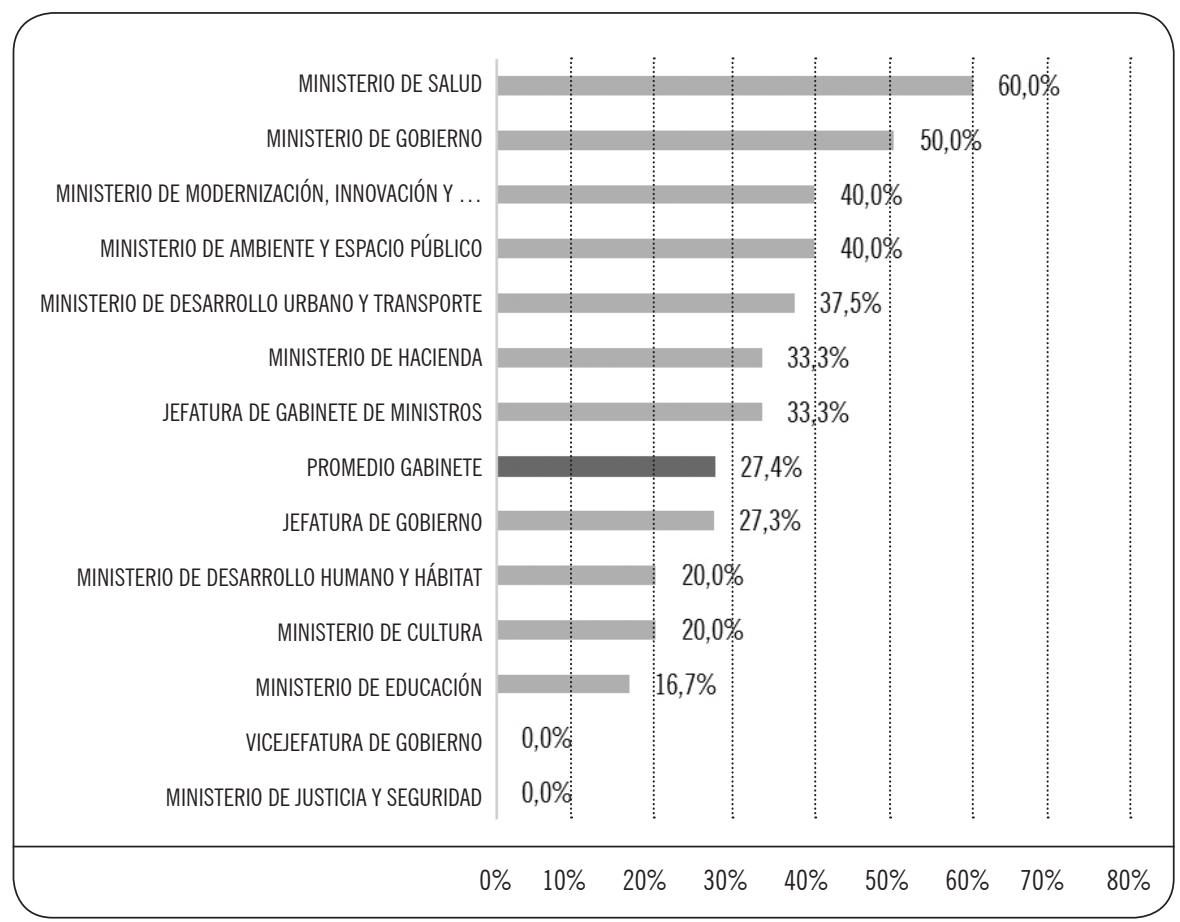

FUENTE: Observatorio de las Elites del CITRA (CONICET-UMET).

Sin embargo, los datos también muestran que tanto la distribución como el peso relativo de los CEO en cada gabinete y en cada dependencia fueron variables. Esto habla tanto de la versatilidad del gobierno de Cambiemos como de la poca precisión que posee la caracterización de "gobierno de los CEO» para dar cuenta de este personal político.

En Nación, este perfil de funcionario estuvo presente en todas las dependencias (todas incluyeron por lo menos a un CEO en su cúpula (CANELO Y CASTELLANI, 20I7). Las dependencias más colonizadas fueron las que integran el área política: la Jefatura de Gabinete de Ministros (con un 69,6\% de CEO), las Secretarías de la Presidencia, los Ministerios de Energía y Minería, de Comunicaciones, y del 
Interior; en todas ellas el peso de los CEO alcanzó casi el 50\%. En el equipo de Macri los CEO desbordaron las áreas económicas, donde históricamente se habían concentrado los hombres de empresa, y se extendieron también a las áreas de decisión política (CANELO Y CASTELLANI, 2OI7).

En contraste, en PBA y CABA el perfil CEO se concentró en algunas áreas. Vidal los agrupó en el Ministerio de Trabajo (cuya cúpula estuvo formada por un 80\% de CEO), en el Ministerio de Asuntos Agrarios $(66,7 \%)$ y en el Ministerio de Economía (60\%); es decir, en áreas más económicas o sociales que políticas. En el gabinete de CABA los Ceo tuvieron más peso en Salud (60\%), Gobierno (50\%) y en los Ministerios de Modernización, de Ambiente y Espacio Público (40\%) y de Desarrollo Urbano (37,5\%).

El limitado alcance de la caracterización «gobierno de los CEO» para dar cuenta de la heterogeneidad del personal político de Cambiemos se reitera cuando se consideran otros aspectos de sus trayectorias ocupacionales. Por ejemplo, al analizar el tipo de cargo, público o privado, que ocupaban inmediatamente antes de ser convocados en 2015 (cargo previo), se observa el peso contundente que tuvo el sector público como espacio de reclutamiento de funcionarios (Cuadro 4).

CUADRO 4:

TIPO DE CARGO PREVIO QUE OCUPABAN LOS FUNCIONARIOS DE NACIÓN, PBA Y CABA

AL MOMENTO DE SER CONVOCADO (EN\% SOBRE EL TOTAL DE CADA GABINETE)

\begin{tabular}{|l|c|c|c|}
\hline GABINETE & OCUPABA & OCUPABA & $\begin{array}{l}\text { SIN DATOS / } \\
\text { TERCER SECTOR }\end{array}$ \\
\hline CARGO PÚBLICO & CARGO PRIVADO & 27,7 \\
NACIÓN & 50,3 & 25,3 & - \\
CABA & 74,7 & 16,5 & 10 \\
\hline
\end{tabular}

FUENTE: Observatorio de las Elites del CITRA (CONICET-UMET). 
El único gabinete donde el reclutamiento en el sector privado sobresale como un rasgo central es el de Nación. Tanto en PBA como en CABA, el verdadero «Plan Semillero» de Cambiemos se desplegó en el Estado: el 74,7\% del gabinete de Vidal y el 73,5\% de Larreta ocupaban cargos públicos al momento de ser convocados (y la mayoría en CABA, como se mencionó más arriba).

El peso decisivo que tuvo el reclutamiento en el sector público se observa también al considerar la trayectoria ocupacional previa de estos funcionarios (es decir, el conjunto de cargos que ocuparon a lo largo de toda su trayectoria ocupacional) lo que agrega una idea de permanencia o de carrera en dicho sector. Los datos muestran la configuración de otro perfil de funcionario, con peso tan importante como el de los CEO, el de los burócratas: el 32,6\% del gabinete de Macri, el 33,7\% del de Vidal y el 46,9\% del de Rodríguez Larreta desarrolló toda su trayectoria ocupacional exclusivamente en el sector público.

La presencia de estos burócratas fue variable en cada gabinete en las distintas áreas de gobierno, como muestran los Gráficos 26, 27 y 28.

La presencia de los burócratas varía en los tres gabinetes, pero tendió a ser importante en las áreas de gobierno vinculadas con el control social (justicia, seguridad). Este tipo de funcionarios con trayectoria exclusiva en el sector público fue reclutado, en Nación, en los Ministerios de Defensa, Turismo, Transporte, Seguridad y Desarrollo Social. En la PBA, los burócratas fueron designados en la Secretaria Legal y Técnica, la Coordinación de la Unidad Gobernador, el Ministerio de Justicia, el de Seguridad y el de Salud. Y en la CABA, en Justicia y Seguridad, la Jefatura de Gobierno y el Ministerio de Cultura. 
GRÁFICO 26:

TIPO DE TRAYECTORIA OCUPACIONAL PREVIA DE LOS FUNCIONARIOS DEL GABINETE DE NACIÓN, POR DEPENDENCIA. N=350

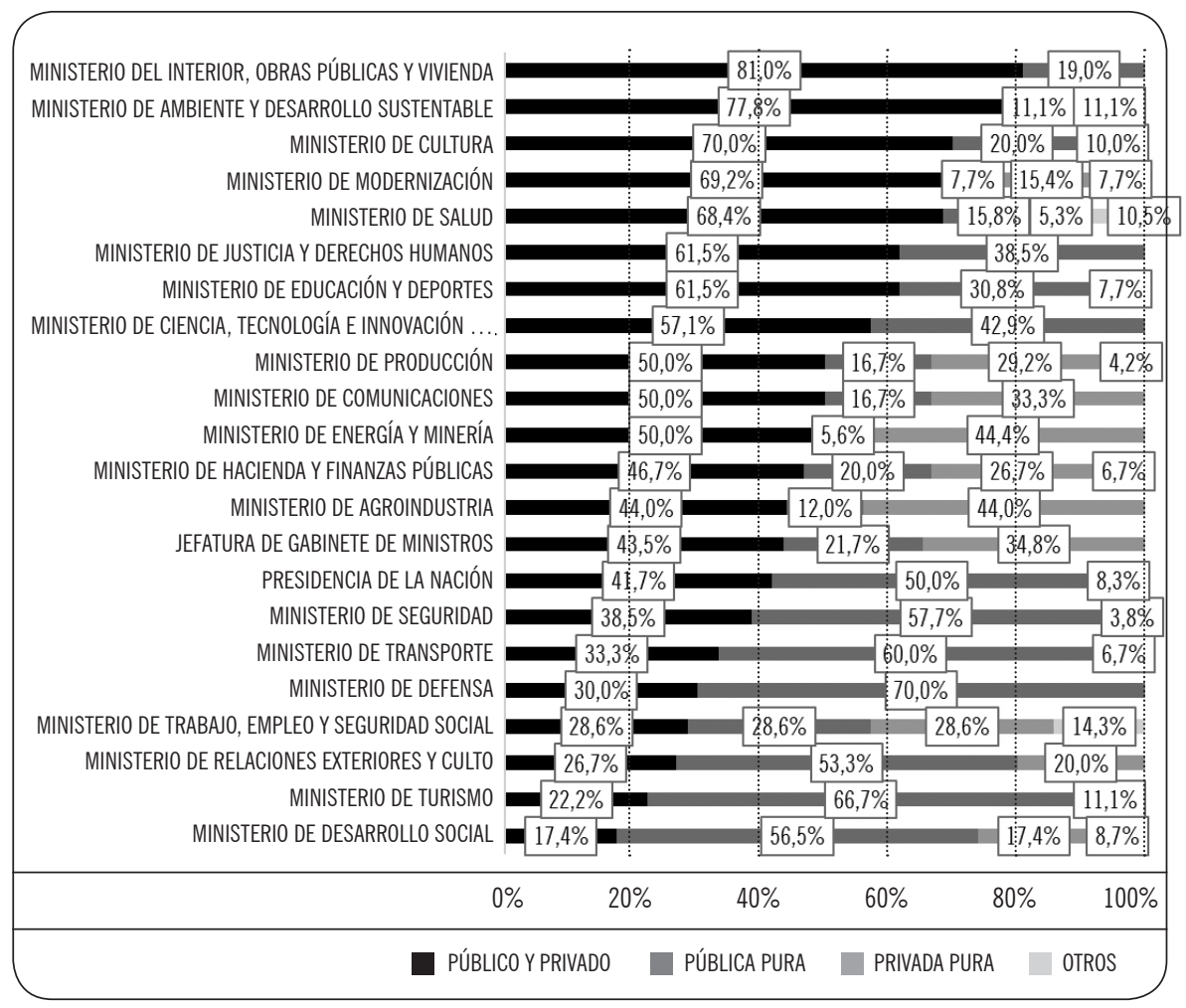

FUENTE: Observatorio de las Elites del CITRA (CONICET-UMET).

NOTA: una «trayectoria público-privada» supone que el funcionario ocupó tanto cargos públicos como privados a lo largo de toda su carrera ocupacional; una «trayectoria pública pura» supone que el funcionario sólo ocupó cargos públicos a lo largo de toda su carrera; y una «trayectoria privada pura» supone que el funcionario sólo ocupó cargos públicos a lo largo de toda su carrera. 
GRÁFICO 27:

TIPO DE TRAYECTORIA OCUPACIONAL PREVIA DE LOS FUNCIONARIOS DEL GABINETE DE PBA, POR DEPENDENCIA, $\mathrm{N}=86$

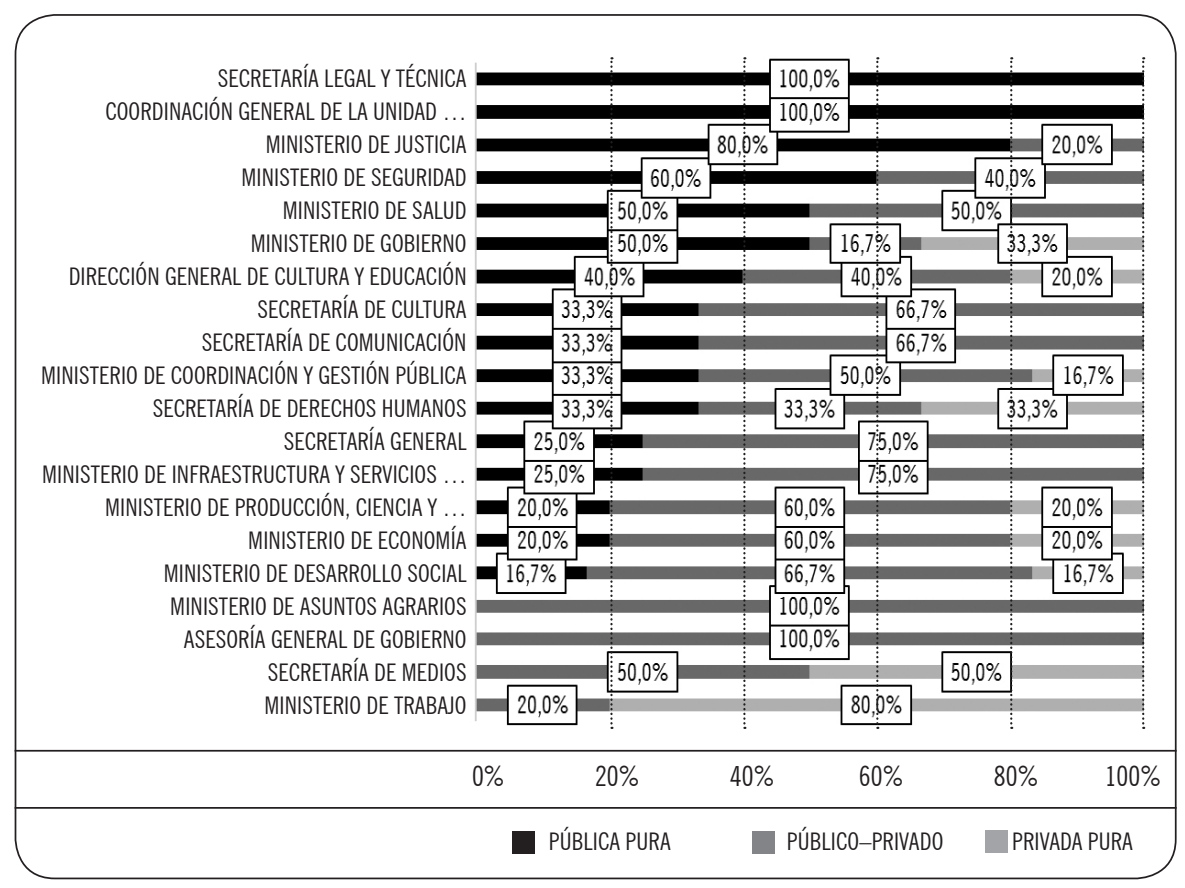

FUENTE: Observatorio de las Elites del CITRA (CONICET-UMET). 
GRÁFICO 28:

TIPO DE TRAYECTORIA OCUPACIONAL PREVIA DE LOS FUNCIONARIOS DEL GABINETE DE CABA, POR DEPENDENCIA. N=81

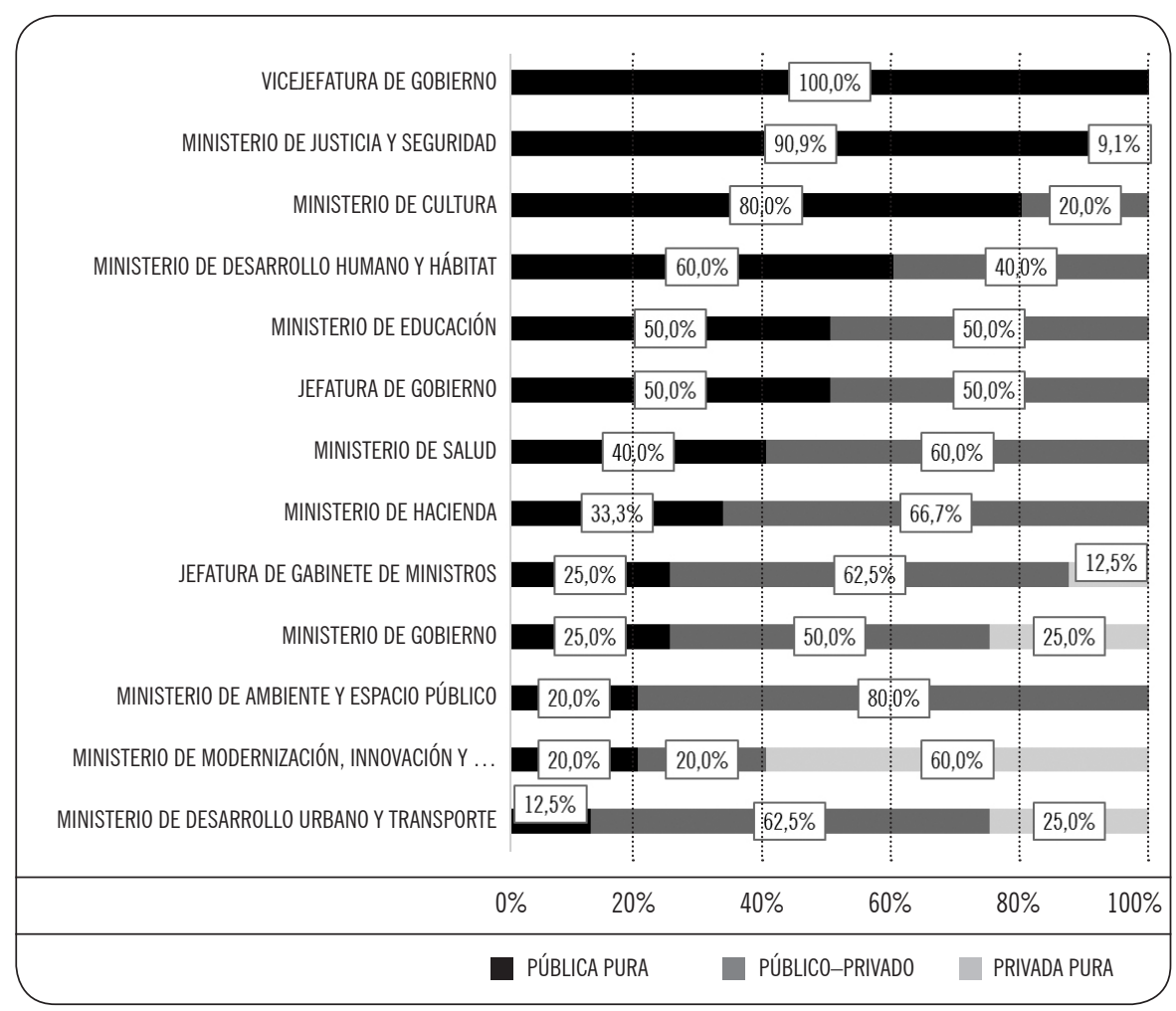

FUENTE: Observatorio de las Elites del CITRA (CONICET-UMET). 


\section{CONCLUSIONES}

Este artículo recurrió al análisis de datos empíricos sobre el perfil sociológico de los tres gabinetes más importantes del gobierno de Cambiemos en la Argentina (el de Nación, el de la PBA y el de CABA), para avanzar en un conocimiento más consistente y sistemático sobre el mismo, específicamente sobre la composición de la elite política que lo llevó adelante, y poner en cuestión parte de los sentidos comunes instalados sobre el mismo.

El análisis empírico y sistemático realizado permitió, primero, caracterizar el perfil sociológico general que presentó esta elite política; segundo, mostrar las similitudes y diferencias que presentaron los tres gabinetes comparados; tercero, identificar continuidades y rupturas en ciertas tendencias generales del reclutamiento de las elites políticas argentinas, vinculando a estos gabinetes con otros; $y$ finalmente, presentar evidencia sobre si durante los ańos de Cambiemos asistimos a la configuración (o no) de una nueva elite política.

Una mirada general sobre los tres gabinetes permitió observar algunas propiedades novedosas de este personal político, aunque también otras compartidas con otras elites políticas de la historia argentina reciente.

Considerados en su conjunto, se trató de funcionarios más jóvenes que aquellos que habían integrado gabinetes anteriores. Sin embargo, el gabinete de Macri parece haber consolidado una tendencia previa, identificada entre otros equipos ejecutivos nacionales, a la progresiva reducción de la edad promedio de los funcionarios. En PBA y en CABA sí se advierte la configuración de una elite política muy joven, aunque la ausencia de datos para otros niveles subnacionales nos impide establecer si el promedio de edad de CABA y PBA es un rasgo compartido con otras elites subnacionales, o no. La relativa baja edad de estos elencos puede ser atribuida a cuestiones coyunturales: por ejemplo, la necesidad de Vidal de reclutar funcionarios que no la superaran demasiado en edad, y la de Larreta de promover a una generación relativamente más joven a las altas esferas de la CABA, dada la sangría de funcionarios que sufrió su gobierno tras el triunfo múltiple de 2015 .

Otra originalidad de estos elencos en su conjunto está vinculada, por ejemplo, con la extendida participación de sus funcionarios en fundaciones, verdadero cursus honorum de esta fuerza política (especialmente del PRO), como ya han señalado otros trabajos (BELLOTTI, MORRESI Y VOMMARO, 2OI5; VOMMARO, 2OI7), participación que no ha sido identificada en otras elites políticas. También se destacan algunos aspectos decisivos de su perfil ocupacional, como el importante peso del perfil CEO 
dentro del conjunto, que en el gobierno de Cambiemos adquirió mayor presencia, distribución e influencia en las áreas políticas de gobierno que en gabinetes previos.

Cuando se analizan las propiedades educativas de los tres gabinetes en general, se observa una combinación de tendencias novedosas con otras de larga data entre las elites políticas argentinas. En lo vinculado con las disciplinas de grado elegidas por los funcionarios, se advierte que la mayoría de los elencos se formó en disciplinas ya tradicionales entre las preferencias de la elite política argentina (ciencias jurídicas y económicas). Pero los datos muestran, además, el peso diferencial que presentan nuevas especialidades educativas, especialmente las vinculadas con la especialización en gestión estatal y gubernamental (ciencias políticas, relaciones internacionales, administración). Esto último sugiere que de mano del gobierno de Cambiemos en sus distintos niveles se consolidó al frente de los espacios ejecutivos una elite de «especialistas en gestión estatal» (CANELO, 20I9), minoritaria o irrelevante en elencos políticos anteriores. Los datos también confirman la preferencia por la educación privada por sobre la pública en la formación de los funcionarios, rasgo que se profundiza a medida que avanza el trayecto educativo de los individuos del grado al posgrado. Este rasgo también distingue a esta elite política de otras, que en el pasado mostraron un mayor peso de la educación pública entre sus cuadros ejecutivos.

La mirada de conjunto muestra, además de rasgos específicos de este personal político, otros generalizados al conjunto de la elite política argentina. Es el caso de la desigualdad de género generalizada: en los tres gabinetes, las mujeres no llegaron a ocupar un cuarto de los cargos más altos, fueron designadas para ocupar los espacios de gestión "tradicionalmente femeninos», estuvieron excluidas de gran parte de las dependencias, y cuando estuvieron presentes tendieron a ocupar los cargos de menor jerarquía.

Cada uno de los tres gabinetes de Cambiemos presentó un perfil diferenciado, lo que revela la considerable versatilidad que presentó el personal político de esta fuerza de gobierno. El análisis comparado revela no solo que el «perfil empresarial» no fue predominante en los tres gabinetes, sino que además la caracterización de "gobierno de los CEO» solo es aplicable para caracterizar la singularidad del elenco nacional, pero no las de los subnacionales.

Además de mostrar un perfil educativo más tradicional que los de PBA y CABA, y de ser el gabinete más «viejo», el gabinete de Nación fue el más colonizado por los CEO. Fue sin dudas el equipo de Macri el que habilitó la construcción de la noción de "gobierno de los CEO», funcionarios que fueron, durante los ańos de 
Cambiemos, uno de los principales arquetipos culturales de su modelo de sociedad «hiperindividualizada», meritocrática y aspiracional (CANELO, 2019). Los gabinetes de Vidal y Rodríguez Larreta fueron territorios de otros grupos profesionales y ocupacionales, entre ellos, los «especialistas en gestión estatal», los funcionarios políticos y los burócratas, que predominaron sobre los CEO en la configuración de los elencos en estos niveles subnacionales.

El análisis empírico realizado también contradice la noción de «nueva generación» que vino a «meterse en política», con la que Cambiemos construyó legitimidad ante la sociedad argentina. Los datos muestran que en sus dinámicas de reclutamiento, Cambiemos consagró muchas de las tendencias más arraigadas en «la vieja política» argentina. Primero, la profunda desigualdad de género que continuó caracterizando la selección del alto funcionariado, que se observó incluso, y en forma muy acentuada, en el gabinete de la primera gobernadora mujer de la provincia de Buenos Aires. Segundo, la importante presencia de funcionarios con amplia participación políticopartidaria previa, en especial en la PBA, muchos de ellos provenientes del justicialismo. Y tercero, un peso decisivo de burócratas estatales que venían desarrollando largas carreras en el sector público, que mientras eran denostados en el discurso público eran muy apreciados en la gestión cotidiana. Así, aunque Cambiemos repitió una y otra vez que «vivir del Estado» era la peor condición posible, con lo que legitimó sus políticas de ajuste y reducción del aparato estatal argentino, consideró muy valiosos, en la práctica, a los burócratas con larga trayectoria en el sector público.

El análisis empírico y sistemático realizado en este artículo ofrece tanto una mirada general sobre la configuración sociológica de la elite política que gobernó la Argentina entre 2015 y 2019, como una mirada comparada entre sus tres gabinetes más importantes, y su puesta en perspectiva con gabinetes anteriores. Los resultados ponen en cuestión varios elementos centrales del relato con el que Cambiemos se legitimó como fuerza política y de gobierno ante nuestra sociedad, hoy parte fundamental de los consensos académicos y de sentido común sobre esta experiencia política. Entre ellos, el de "gobierno de los CEO», el de «nueva generación», y en suma, el de que se trató de una «elite política nueva».

Si las novedades que trajo Cambiemos a la configuración del personal político argentino, también reseñadas aquí, determinarán nuevos criterios de reclutamiento para las elites políticas del futuro, o si permanecerán acotados a dinámicas específicas de la experiencia de 2015-20I9, es algo que deberá ser evaluado mediante nuevos trabajos sobre éstos y otros gabinetes. 


\section{Referencias bibliográficas}

AMORIM NETO, OCTAVIO (1998): "Cabinet Formation in Presidential Regimes: An Analysis of 10 Latin American Countries", en: Latin American Studies Association Congress, Illinois, s.p. BELLONI, PAULA Y CANTAMUTTO, FRANCISCO (coords.) (2019): La economía política de Cambiemos. Ensayos sobre un nuevo ciclo neoliberal en la Argentina, Buenos Aires, Batalla de Ideas.

BELLOTTI, ALEJANDRO; MORRESI, SERGIO Y VOMMARO, GABRIEL (2015): Mundo PRO: anatomía de un partido fabricado para ganar, Buenos Aires, Planeta. CAMERLO, MARCELO (2013): «Gabinetes de partido único y democracias presidenciales. Indagaciones a partir del caso argentino», en: América Latina Hoy, No 64, pp. 119-142.

CAMINOTTI, MARIANA Y FREIDENBERG, FLAVIA (2016): «Federalismo electoral, fortaleza de las cuotas de género y representación política de las mujeres en los ámbitos subnacionales en Argentina y México», en: Revista mexicana de ciencias políticas y sociales, 61 (228), pp. 121-144.

CANELO, PAULA (2016): «La militarización del Estado durante la última dictadura militar argentina. Un estudio de los gabinetes del Poder Ejecutivo Nacional entre 1976 y 1983», en: Historia Crítica, N62, pp. 57-75.

CANELO, PAULA (2019): ¿Cambiamos? La batalla cultural por el sentido común de los argentinos, Buenos Aires, Siglo XXI.

CANELO, PAULA Y CASTELLANI, ANA (2017): Perfil sociológico de los miembros del gabinete inicial del presidente Mauricio Macri, Informe de Investigación $n^{\circ} 1$ del Observatorio de las Elites del CITRA (CONICET-UMET). Disponible en: < https://citra. org.ar/wp-content/uploads/2020/01/2016_Informe_1_Observatorio_de_las_Elites.pdf > (2/4/2020).
CANELO, PAULA Y MARINO, JAIME (2020): «¿Elites y antielites? Estudio comparado del perfil sociológico de los gabinetes iniciales de Cristina Fernandez de Kirchner y de Mauricio Macri (2011 y 2015)», Observatorio de las Elites del CITRA (CONICETUMET), mimeo.

CANELO, PAULA Y LASCURAIN, MARÍA CECILIA (2017): ¿Quiénes gobiernan la provincia de Buenos Aires? El perfil sociológico del gabinete de María Eugenia Vidal, Informe de Investigación $n^{\circ} 3$ del Observatorio de las Elites del CITRA (CONICET-UMET). Disponible en: <https://citra.org.ar/ wp-content/uploads/2020/01/2017_Informe_3_ Observatorio_de_las_Elites.pdf > (2/4/2020). CANELO, PAULA Y HEREDIA, MARIANA (comps.) (2019): Los puentes y las puertas. Las fronteras de la política argentina a través de sus elites, Buenos Aires, UNSAM Edita.

CANELO, PAULA, CASTELLANI, ANA Y HEREDIA, MARIANA (2015): «Perfil sociológico de las elites políticas y económicas argentinas entre 1976 y 2001", en: XI Jornadas de Sociología de la Universidad de Buenos Aires, Buenos Aires, 13-17 de julio. CHASQUETTI, DANIEL; BUQUET, DANIEL Y CARDARELLO, ANTONIO (2013): «La designación de gabinetes en Uruguay: estrategia legislativa, jerarquía de los ministerios y afiliación partidaria de los ministros», en: América Latina Hoy, № 64, pp. 15-40. DÁVILA, MIREYA; OLIVARES, ALEJANDRO Y AVENDAÑO, OCTAVIO (2013): «Los gabinetes de la Concertación en Chile (1990-2010)», en: América Latina Hoy, No64, pp. 67-94.

DE IMAZ, JOSÉ LUIS (1964): Los que mandan, Buenos Aires, EUDEBA.

DE LUCA, MIGUEL (2011): «Del príncipe y sus secretarios. Cinco apuntes sobre gabinetes presidenciales en la Argentina reciente», en: MALAMUD, 
ANDRÉS Y DE LUCA, MIGUEL (eds.). La política en tiempos de los Kirchner, Buenos Aires, EUDEBA. pp. 37-48.

ESCOBAR LEMMON, MARÍA C. Y TAYLOR ROBINSON, MICHELLE M. (2009): «Getting to the top. Career paths of women in Latin American Cabinets", en: Political research quarterly, 62 (4), pp. 685-699. FIDANZA, ANDRÉS (2019): Durán Barba. El mago de la felicidad, Buenos Aires, Planeta.

GENÉ, MARIANA (2019): La rosca política. El oficio de los armadores delante y detrás de escena (o el discreto encanto del toma y daca), Buenos Aires, Siglo XXI.

GIORGI, GUIDO (2014): «Ministros y ministerios de la Nación: Un aporte prosopográfico para el estudio del gabinete nacional», en: Apuntes. Revista de Ciencias Sociales, № 74, Vol. XLI, pp. 103-139. GIORGI, GUIDO (2015): Modos de acceso y circulación por el gobierno nacional. Perfiles, sociabilidades y redes socio-políticas y religiosas de los cuadros de gobierno de Desarrollo Social de la Nación. Argentina, 1994-2011, Tesis de Doctorado UBA-EHESS.

GRASSI, ESTELA (1989): La mujer y la profesión de asistente social. El control de la vida cotidiana, Buenos Aires, Hvmanitas.

HEREDIA, MARIANA (2015): Cuando los economistas alcanzaron el poder (o cómo se gestó la confianza de los expertos), Buenos Aires, Siglo XXI Editores. HEREDIA, MARIANA; GENÉ, MARIANA Y PERELMITER, LUISINA (2012): «Hacia una sociohistoria del gabinete nacional», en: PolHis, 5, 9, pp. 284-290.

JOIGNANT, ALFREDO Y GÜELL, PEDRO (eds.) (2011): Notables, tecnócratas y mandarines. Elementos de sociología de las elites en Chile (1990-2010), Santiago de Chile, Universidad Diego Portales. KROOK, MONA LENA Y O'BRIEN, DIANA Z. (2012): «AII the president's men? The Appointment of female cabinet ministers worldwide», en: The journal of politics, 74 (3), pp. 840-855.

LASCURAIN, MARÍA CECILIA (2017): «Los colaboradores del gobernador. Una tipología del gabinete inicial de Carlos Reutemann (1991)», en: III Jornadas Interdisciplinarias de Jóvenes Investigadores en Ciencias Sociales, IDAES-UNSAM, Buenos Aires, 6,7 y 8 de septiembre.

MAURO, SEBASTIÁN (2015): «La transformación del sistema político argentino y sus nuevos actores. La construcción Propuesta Republicana como partido político nacional (2003-2013)», en: Analecta política, 5 (9), 407-430.

MORRESI, SERGI0 (2015): «"Acá somos todos democráticos". El PRO y las relaciones entre la derecha y la democracia en Argentina», en: VOMMARO, GABRIEL Y MORRESI, SERGIO (orgs.). "Hagamos equipo». PRO y la construcción de la nueva derecha en Argentina, Buenos Aires, Ediciones Universidad de General Sarmiento, pp. 163-201. NATANSON, JOSÉ (2018): ¿Por qué? La rápida agonía de la Argentina kirchnerista y la brutal eficacia de una nueva derecha, Buenos Aires, Siglo XXI. OBSERVATORIO NACIONAL DE VIOLENCIA CONTRA LAS MUJERES (2018): Indicadores nacionales de género, Ministerio de Salud y Desarrollo Social de la Nación, Instituto Nacional de las Mujeres. POMARES, JULIA; LEIRAS, MARCELO; PAGE, MARÍA; ZÁRATE, SOLEDAD; ABDALA, MARÍA BELÉN (2014): Los caballeros de la mesa chica. La lógica de designación de los gabinetes desde 1983, en: Documento de Políticas Públicas/Análisis №138, Buenos Aires, CIPPEC.

ROVETTO, FLORENCIA E IRENE LIS GINDIN (2019): La Argentina de Cambiemos, Rosario, Universidad Nacional de Rosario Editora.

SALERNO, AGUSTín (2019): «La cara social de la nueva derecha argentina. Perfiles políticos y atributos de 
gestión socio-asistencial del PRO y de Cambiemos en la Nación, la provincia de Buenos Aires y la ciudad de Buenos Aires (2007-2019)». Tesis Doctoral. Doctorado en Sociología del IDAES-UNSAM. SAWICKI, FRÉDÉRIC (1999): "Classer les hommes politiques. Les usages des indicateurs de position sociale pour la compréhension de la professionnalisation politique», en: OFFERLÉ, MICHEL (dir.). La profession politique, XIXe-XXe siècle, Paris, Belin, pp. 135-170.

VOMMARO, GABRIEL (2014): «"Meterse en política": la construcción de PRO y la renovación de la centroderecha argentina», en: Nueva Sociedad, 254 (noviembre-diciembre), pp. 57-72.
VOMMARO, GABRIEL (2017): La larga marcha de Cambiemos. La construcción silenciosa de un proyecto de poder, Buenos Aires, Siglo XXI.

VOMMARO, GABRIEL Y ARMESTO, MELCHOR (2015): «¿Nuevos políticos en el partido, viejos políticos en las listas? Reclutamiento partidario y división del trabajo político en PRO, en la Ciudad Autónoma de Buenos Aires», en: Pasado Abierto,1(2), pp. 110-132.

VOMMARO, GABRIEL Y MORRESI SERGIO (orgs.) (2015): "Hagamos equipo». PRO y la construcción de la nueva derecha en Argentina, Buenos Aires, Ediciones Universidad de General Sarmiento. 